4

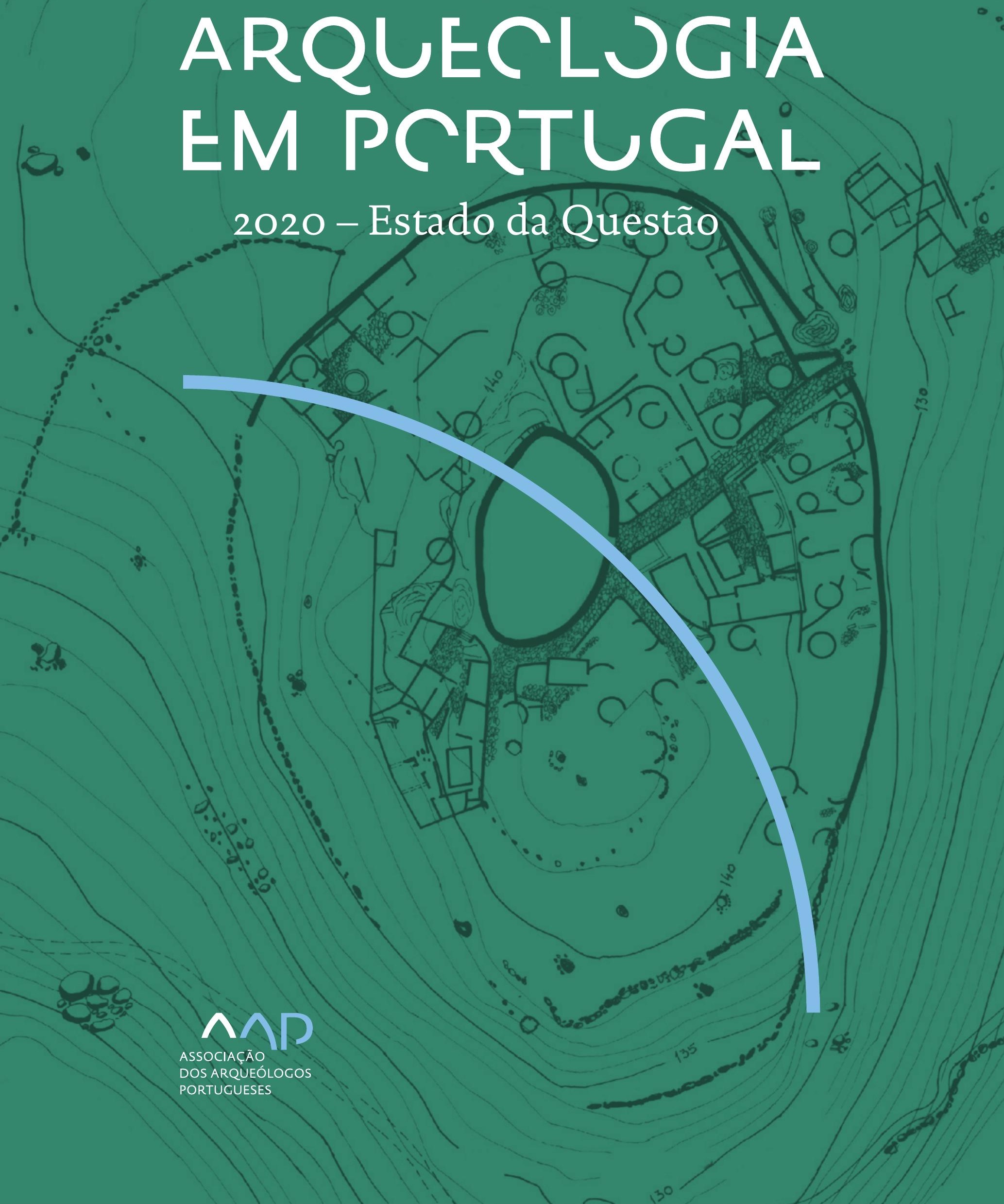


Coordenação editorial: José Morais Arnaud, César Neves e Andrea Martins Design gráfico: Flatland Design

AAP - ISBN: 978-972-9451-89-8

CITCEM - ISBN: 978-989-8970-25-1

Associação dos Arqueólogos Portugueses e CITCEM

Lisboa, 2020

O conteúdo dos artigos é da inteira responsabilidade dos autores. Sendo assim a Associação dos Arqueólogos Portugueses declina qualquer responsabilidade por eventuais equívocos ou questões de ordem ética e legal.

Desenho de capa:

Planta do castro de Monte Mozinho (Museu Municipal de Penafiel).

\section{$\hat{\wedge} \mathrm{P}$}

DOS ARQUEÓLOGOS PORTUGUESES

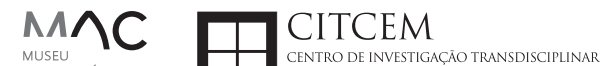
MUSEU
ARQUELLÓGICO
DO CARMO
U.PORTO

FLUP FACULDADE DE LETRAS
UNIVERSIDADE DO PORTO

Apoio

EC para a Ciência 


\section{Índice}

15 Prefácio

José Morais Arnaud

\section{Historiografia e Teoria}

17 Território, comunidade, memória e emoção: a contribuição da história da arqueologia (algumas primeiras e breves reflexões)

Ana Cristina Martins

25 Como descolonizar a arqueologia portuguesa?

Rui Gomes Coelho

41 Arqueologia e Modernidade: uma revisitação pessoal e breve de alguns aspetos da obra homónima de Julian Thomas de 2004

Vítor Oliveira Jorge

57 Dados para a História das Mulheres na Arqueologia portuguesa, dos finais do século XIX aos inícios do século XX: números, nomes e tabelas

Filipa Dimas / Mariana Diniz

73 Retractos da arqueologia portuguesa na imprensa: (in)visibilidades no feminino

Catarina Costeira / Elsa Luís

85 Arqueologia e Arqueólogos no Norte de Portugal Jacinta Bugalhão

101 Vieira Guimarães (1864-1939) e a arqueologia em Tomar: uma abordagem sobre o território e as gentes

João Amendoeira Peixoto / Ana Cristina Martins

115 Os memoráveis? A arqueologia algarvia na imprensa nacional e regional na presente centúria (2001-2019): características, visões do(s) passado(s) e a arqueologia

enquanto marca

Frederico Agosto / João Silva

129 A Evolução da Arqueologia Urbana e a Valorização Patrimonial no Barlavento Algarvio: Os casos de Portimão e Silves

Artur Mateus / Diogo Varandas / Rafael Boavida

\section{Gestão, Valorização e Salvaguarda do Património}

145 O Caderno Reivindicativo e as condições de trabalho em Arqueologia Miguel Rocha / Liliana Matias Carvalho / Regis Barbosa / Mauro Correia / Sara Simões / Jacinta Bugalhão / Sara Brito / Liliana Veríssimo Carvalho / Richard Peace / Pedro Peça / Cézer Santos

155 Os Estudos de Impacte Patrimonial como elemento para uma estratégia sustentável de minimização de impactes no âmbito de reconversões agrícolas Tiago do Pereiro

165 Salvaguarda de Património arqueológico em operações florestais: gestão e sensibilização Filipa Bragança / Gertrudes Zambujo / Sandra Lourenço / Belém Paiva / Carlos Banha / Frederico Tatá Regala / Helena Moura / Jacinta Bugalhão / João Marques / José Correia / Pedro Faria / Samuel Melro

179 Os valores do Património: uma investigação sobre os Sítios Pré-históricos de Arte Rupestre do Vale do Rio Côa e de Siega Verde José Paulo Francisco 
189 Conjugando recursos arqueológicos e naturais para potenciar as visitas ao Geoparque Litoral de Viana do Castelo (Noroeste de Portugal)

Hugo A. Sampaio / Ana M.S. Bettencourt / Susana Marinho / Ricardo Carvalhido

203 Áreas de Potencial Arqueológico na Região do Médio Tejo: Modelo Espacial Preditivo Rita Ferreira Anastácio / Ana Filipa Martins / Luiz Oosterbeek

223 Património Arqueológico e Gestão Territorial: O contributo da Arqueologia para a revisão do PDM de Avis

Ana Cristina Ribeiro

237 A coleção arqueológica do extinto Museu Municipal do Porto - Origens, Percursos e Estudos

Sónia Couto

251 Valpaços - uma nova carta arqueológica

Pedro Pereira / Maria de Fátima Casares Machado

263 Arqueologia na Cidade de Peniche

Adriano Constantino / Luís Rendeiro

273 Arqueologia Urbana: a cidade de Lagos como caso de Estudo Cátia Neto

285 Estratégias de promoção do património cultural subaquático nos Açores. O caso da ilha do Faial

José Luís Neto / José Bettencourt / Luís Borges / Pedro Parreira

297 Carta Arqueológica da Cidade Velha: Uma primeira abordagem

Jaylson Monteiro / Nireide Tavares / Sara da Veiga / Claudino Ramos / Edson Brito /

Carlos Carvalho / Francisco Moreira / Adalberto Tavares

311 Antropologia Virtual: novas metodologias para a análise morfológica e funcional Ricardo Miguel Godinho / Célia Gonçalves

\section{Didáctica da Arqueologia}

327 Como os projetos de Arqueologia podem contribuir para uma comunidade culturalmente mais consciente Alexandra Figueiredo / Claúdio Monteiro / Adolfo Silveira / Ricardo Lopes

337 Educação Patrimonial - Um cidadão esclarecido é um cidadão ativo! Ana Paula Almeida

351 A aproximação da Arqueologia à sala de aula: um caso de estudo no $3^{\circ}$ ciclo do Ensino Básico Luís Serrão Gil

363 Arqueologia 3.o - Pensar e comunicar a Arqueologia para um futuro sustentável Mónica Rolo

377 “Conversa de Arqueólogos" - Divulgar a Arqueologia em tempos de Pandemia Diogo Teixeira Dias

389 Escola Profissional de Arqueologia: desafios e oportunidades Susana Nunes / Dulcineia Pinto / Júlia Silva / Ana Mascarenhas

399 Os Museus de Arqueologia e os Jovens: a oferta educativa para o público adolescente Beatriz Correia Barata / Leonor Medeiros

411 O museu universitário como mediador entre a ciência e a sociedade: o exemplo da secção de arqueologia no Museu de História Natural e da Ciência da Universidade do Porto (MHNC-UP)

Rita Gaspar 
421 Museu de Lanifícios: Real Fábrica de Panos. Atividades no âmbito da Arqueologia Beatriz Correia Barata / Rita Salvado

427 Arqueologia Pública e o caso da localidade da Mata (Torres Novas) Cláudia Manso / Ana Rita Ferreira / Cristiana Ferreira / Vanessa Cardoso Antunes

431 Do sítio arqueológico ao museu: um percurso (também) didático Lídia Fernandes

447 Estão todos convidados para a Festa! E para dançar também... O projecto do Serviço Educativo do Museu Arqueológico do Carmo na $5^{\underline{a}}$ Edição da Festa da Arqueologia Rita Pires dos Santos

459 O “Clã de Carenque”, um projeto didático de arqueologia Eduardo Gonzalez Rocha

469 Mediação cultural: peixe que puxa carroça nas Ruínas Romanas de Troia Inês Vaz Pinto / Ana Patrícia Magalhães / Patrícia Brum / Filipa Santos

481 Didática Arqueológica, experiências do Projeto Mértola Vila Museu Maria de Fátima Palma / Clara Rodrigues / Susana Gómez / Lígia Rafael

\section{Arte Rupestre}

497 Os inventários de arte rupestre em Portugal Mila Simões de Abreu

513 O projeto FIRST-ART - conservação, documentação e gestão das primeiras manifestações de arte rupestre no Sudoeste da Península Ibérica: as grutas do Escoural e Maltravieso Sara Garcês / Hipólito Collado / José Julio García Arranz / Luiz Oosterbeek / António Carlos Silva / Pierluigi Rosina / Hugo Gomes / Anabela Borralheiro Pereira / George Nash / Esmeralda Gomes / Nelson Almeida / Carlos Carpetudo

523 Trabalhos de documentação de arte paleolítica realizados no âmbito do projeto PalæoCôa André Tomás Santos / António Fernando Barbosa / Luís Luís / Marcelo Silvestre / Thierry Aubry

537 Imagens fantasmagóricas, silhuetas elusivas: as figuras humanas na arte do Paleolítico Superior da região do Côa Mário Reis

$55^{1}$ Os motivos zoomórficos representados nas placas de tear de Vila Nova de São Pedro (Azambuja, Portugal) Andrea Martins / César Neves / José M. Arnaud / Mariana Diniz

571 Arte Rupestre do Monte de Góios (Lanhelas, Caminha). Síntese dos resultados dos trabalhos efectuados em 2007-2009 Mário Varela Gomes

599 Gravuras rupestres de barquiformes no Monte de S. Romão, Guimarães, Noroeste de Portugal Daniela Cardoso

613 Círculos segmentados gravados na Bacia do Rio Lima (Noroeste de Portugal): contributos para o seu estudo Diogo Marinho / Ana M.S. Bettencourt / Hugo Aluai Sampaio

631 Equídeos gravados no curso inferior do Rio Mouro, Monção (NW Portugal). Análise preliminar Coutinho, L.M. / Bettencourt, A.M.S / Sampaio, Hugo A.S

645 Paletas na Arte Rupestre do Noroeste de Portugal. Inventário preliminar Bruna Sousa Afonso / Ana M. S. Bettencourt / Hugo A. Sampaio 


\section{Pré-História}

661 O projeto Miño/Minho: balanço de quatro anos de trabalhos arqueológicos Sérgio Monteiro-Rodrigues / João Pedro Cunha-Ribeiro / Eduardo Méndez-Quintas / Carlos Ferreira / Pedro Xavier / José Meireles / Alberto Gomes / Manuel Santonja / Alfredo Pérez-González

677 A ocupação paleolítica da margem esquerda do Baixo Minho: a indústria lítica do sítio de Pedreiras 2 (Monção, Portugal) e a sua integração no contexto regional Carlos Ferreira / João Pedro Cunha-Ribeiro / Sérgio Monteiro-Rodrigues / Eduardo Méndez-Quintas / Pedro Xavier / José Meireles / Alberto Gomes / Manuel Santonja / Alfredo Pérez-González

693 O sítio acheulense do Plistocénico médio da Gruta da Aroeira Joan Daura / Montserrat Sanz / Filipa Rodrigues / Pedro Souto / João Zilhão

703 As sociedades neandertais no Barlavento algarvio: modelos preditivos com recurso aos SIG

Daniela Maio

715 A utilização de quartzo durante o Paleolítico Superior no território dos vales dos rios Vouga e Côa

Cristina Gameiro / Thierry Aubry / Bárbara Costa / Sérgio Gomes / Luís Luís / Carmen Manzano / André Tomás Santos

733 Uma perspetiva diacrónica da ocupação do concheiro do Cabeço da Amoreira (Muge, Portugal) a partir da tecnologia lítica Joana Belmiro / João Cascalheira / Célia Gonçalves

745 Novos dados sobre a Pré-história Antiga no concelho de Palmela. A intervenção arqueológica no sítio do Poceirão I

Michelle Teixeira Santos

757 Problemas em torno de Datas Absolutas Pré-Históricas no Norte do Alentejo Jorge de Oliveira

771 Povoamento pré-histórico nas áreas montanhosas do NO de Portugal: o Abrigo 1 de Vale de Cerdeira Pedro Xavier / José Meireles / Carlos Alves

783 Apreciação do povoamento do Neolítico Inicial na Baixa Bacia do Douro. A Lavra I (Serra da Aboboreira) como caso de estudo Maria de Jesus Sanches

797 O Processo de Neolitização na Plataforma do Mondego: os dados do Sector C do Outeiro dos Castelos de Beijós (Carregal do Sal)

João Carlos de Senna-Martinez / José Manuel Quintã Ventura / Andreia Carvalho / Cíntia Maurício

823 Novos trabalhos na Lapa da Bugalheira (Almonda, Torres Novas) Filipa Rodrigues / Pedro Souto / Artur Ferreira / Alexandre Varanda / Luís Gomes / Helena Gomes / João Zilhão

837 A pedra polida e afeiçoada do sítio do Neolítico médio da Moita do Ourives (Benavente, Portugal)

César Neves

857 Casal do Outeiro (Encarnação, Mafra): novos contributos para o conhecimento do povoamento do Neolítico final na Península de Lisboa.

Cátia Delicado / Carlos Maneira e Costa / Marta Miranda / Ana Catarina Sousa

873 Stresse infantil, morbilidade e mortalidade no sítio arqueológico do Neolítico Final/ Calcolítico ( $4^{\circ}$ e $3^{\circ}$ milénio a.C.) do Monte do Carrascal 2 (Ferreira do Alentejo, Beja) Liliana Matias de Carvalho / Sofia N. Wasterlain 
885 Come together: O Conjunto Megalítico das Motas (Monção, Viana do Castelo) e as expressões Campaniformes do Alto Minho Ana Catarina Basílio / Rui Ramos

899 Trabalhos arqueológicos no sítio Calcolítico da Pedreira do Poio Carla Magalhães / João Muralha / Mário Reis / António Batarda Fernandes

913 O sítio arqueológico de Castanheiro do Vento. Da arquitectura do sítio à arquitectura de um território João Muralha Cardoso

925 Estudo zooarqueológico das faunas do Calcolítico final de Vila Nova de São Pedro (Azambuja, Portugal): Campanhas de 2017 e 2018 Cleia Detry / Ana Catarina Francisco / Mariana Diniz / Andrea Martins / César Neves / José Morais Arnaud

943 As faunas depositadas no Museu Arqueológico do Carmo provenientes de Vila Nova de São Pedro (Azambuja): as campanhas de 1937 a 1967 Ana Catarina Francisco / Cleia Detry / César Neves / Andrea Martins / Mariana Diniz / José Morais Arnaud

959 Análise funcional de material lítico em sílex do castro de Vila Nova de S. Pedro (Azambuja, Portugal): uma primeira abordagem Rafael Lima

971 O recinto da Folha do Ouro 1 (Serpa) no contexto dos recintos de fossos calcolíticos alentejanos

António Carlos Valera / Tiago do Pereiro / Pedro Valério / António M. Monge Soares

\section{Proto-História}

987 Produção de sal marinho na Idade do Bronze do noroeste Português. Alguns dados para uma reflexão

Ana M. S. Bettencourt / Sara Luz / Nuno Oliveira / Pedro P. Simões / Maria Isabel C. Alves / Emílio Abad-Vidal

1001 A estátua-menir do Pedrão ou de São Bartolomeu do Mar (Esposende, noroeste de Portugal) no contexto arqueológico da fachada costeira de entre os rios Neiva e Cávado Ana M. S. Bettencourt / Manuel Santos-Estévez / Pedro Pimenta Simões / Luís Gonçalves

1015 O Castro do Muro (Vandoma/Baltar, Paredes) - notas para uma biografia de ocupação da Idade do Bronze à Idade Média

Maria Antónia D. Silva / Ana M. S. Bettencourt / António Manuel S. P. Silva / Natália Félix

1031 Do Bronze Final à Idade Média - continuidades e hiatos na ocupação de Povoados em Oliveira de Azeméis João Tiago Tavares / Adriaan de Man

1041 As faunas do final da Idade do Bronze no Sul de Portugal: leituras desde o Outeiro do Circo (Beja)

Nelson J. Almeida / Íris Dias / Cleia Detry / Eduardo Porfírio / Miguel Serra

1055 A Espada do Monte das Oliveiras (Serpa) - uma arma do Bronze Pleno do Sudoeste Rui M. G. Monge Soares / Pedro Valério / Mariana Nabais / António M. Monge Soares

1065 São Julião da Branca (Albergaria-a-Velha) - Investigação e valorização de um povoado do Bronze Final

António Manuel S. P. Silva / Paulo A. P. Lemos / Sara Almeida e Silva / Edite Martins de Sá

1083 Do castro de S. João ao Mosteiro de Santa Clara: notícia de uma intervenção arqueológica, em Vila do Conde Rui Pinheiro 
1095 O castro de Ovil (Espinho), um quarto de século de investigação - resultados e questões em aberto

Jorge Fernando Salvador / António Manuel S. P. Silva

1111 O Castro de Salreu (Estarreja), um povoado proto-histórico no litoral do Entre Douro e Vouga

Sara Almeida e Silva / António Manuel S. P. Silva / Paulo A. P. Lemos / Edite Martins de Sá

1127 Castro de Nossa Senhora das Necessidades (Sernancelhe): uma primeira análise artefactual Telma Susana O. Ribeiro

${ }_{1141}$ A cividade de Bagunte. O estado atual da investigação Pedro Brochado de Almeida

1153 Zoomorfos na cerâmica da Idade do Ferro no NW Peninsular: inventário, cronologias e significado Nuno Oliveira / Cristina Seoane

1163 Vasos gregos em Portugal: diferentes maneiras de contar a história do intercâmbio cultural na Idade do Ferro

Daniela Ferreira

1175 Os exotica da necrópole da Idade do Ferro do Olival do Senhor dos Mártires (Alcácer do Sal) no seu contexto regional

Francisco B. Gomes

\section{Antiguidade Clássica e Tardia}

1191 O uso de madeira como combustível no sítio da Quinta de Crestelos (Baixo Sabor): da Idade do Ferro à Romanização Filipe Vaz / João Tereso / Sérgio Simões Pereira / José Sastre / Javier Larrazabal Galarza / Susana Cosme / José António Pereira / Israel Espi

1207 Cultivos de Época Romana no Baixo Sabor: continuidade em tempos de mudança? João Pedro Tereso / Sérgio Simões Pereira / Filipe Santos / Luís Seabra / Filipe Vaz

1221 A casa romana na Hispânia: aplicação dos modelos itálicos nas províncias ibéricas Fernanda Magalhães / Diego Machado / Manuela Martins

1235 As pinturas murais romanas da Rua General Sousa Machado, n. ${ }^{5}$ 1, Chaves José Carvalho

1243 Trás do Castelo (Vale de Mir, Pegarinhos, Alijó) - Uma exploração agrícola romana do Douro

Tony Silvino / Pedro Pereira

1255 A sequência de ocupação no quadrante sudeste de Bracara Augusta: as transformações de uma unidade doméstica Lara Fernandes / Manuela Martins

1263 Os Mosaicos com decoração geométrica e geométrico-vegetalista dos sítios arqueológicos da área do Conuentus Bracaraugustanus. Novas abordagens quanto à conservação, restauro, decoração e datação Maria de Fátima Abraços / Licínia Wrench

1277 “Casa Romana” do Castro de São Domingos (Cristelos, Lousada): Escavação, Estudo e Musealização Paulo André de P. Lemos

1291 A arqueobotânica no Castro de Guifões (Matosinhos, Noroeste de Portugal): O primeiro estudo carpológico

Luís Seabra / Andreia Arezes / Catarina Magalhães / José Varela / João Pedro Tereso 
1305 Um Horreum Augustano na Foz do Douro (Monte do Castelo de Gaia, Vila Nova de Gaia) Rui Ramos

1311 Ponderais romanos na Lusitânia: padrões, formas, materiais e contextos de utilização Diego Barrios Rodríguez

1323 Um almofariz centro-itálico na foz do Mondego

Marco Penajoia

1335 Estruturas romanas de Carnide - Lisboa Luísa Batalha / Mário Monteiro / Guilherme Cardoso

1347 O contexto funerário do sector da "necrópole NO" da Rua das Portas de S. Antão (Lisboa): o espaço, os artefactos, os indivíduos e a sua interconectividade na interpretação do passado Sílvia Loja, José Carlos Quaresma, Nelson Cabaço, Marina Lourenço, Sílvia Casimiro, Rodrigo Banha da Silva, Francisca Alves-Cardoso

${ }_{1361}$ Povoamento em época Romana na Amadora - resultados de um projeto pluridisciplinar Gisela Encarnação / Vanessa Dias

1371 A Arquitectura Residencial em Mirobriga (Santiago do Cacém): contributo a partir de um estudo de caso Filipe Sousa / Catarina Felício

${ }_{1385}$ O fim do ciclo. Saneamento e gestão de resíduos nos edifícios termais de Mirobriga (Santiago do Cacém)

Catarina Felício / Filipe Sousa

1399 Balsa, Topografia e Urbanismo de uma Cidade Portuária Vítor Silva Dias / João Pedro Bernardes / Celso Candeias / Cristina Tété Garcia

1413 No Largo das Mouras Velhas em Faro (2017): novas evidências da necrópole norte de Ossonoba e da sua ocupação medieval Ricardo Costeira da Silva / Paulo Botelho / Fernando Santos / Liliana Nunes

1429 Instrumentos de pesca recuperados numa fábrica de salga em Ossonoba (Faro) Inês Rasteiro / Ricardo Costeira da Silva / Paulo Botelho

1439 A Necrópole Romana do Eirô, Duas Igrejas (Penafiel): intervenção arqueológica de 2016 Laura Sousa / Teresa Soeiro

1457 Ritual, descarte ou afetividade? A presença de Canis lupus familiaris na Necrópole Noroeste de Olisipo (Lisboa)

Beatriz Calapez Santos / Sofia Simões Pereira / Rodrigo Banha da Silva / Sílvia Casimiro / Cleia Detry / Francisca Alves Cardoso

1467 Dinâmicas económicas em Bracara na Antiguidade Tardia Diego Machado / Manuela Martins / Fernanda Magalhães / Natália Botica

1479 Cerâmicas e Vidros da Antiguidade Tardia do Edifício sob a Igreja do Bom Jesus (Vila Nova de Gaia) Joaquim Filipe Ramos

1493 Novos contributos para a topografia histórica de Mértola no período romano e na Antiguidade Tardia Virgílio Lopes

\section{8. Época Medieval}

1511 Cerâmicas islâmicas no Garb setentrional "português": algumas evidências e incógnitas Constança dos Santos / Helena Catarino / Susana Gómez / Maria José Gonçalves / Isabel Inácio / Gonçalo Lopes / Jacinta Bugalhão / Sandra Cavaco / Jaquelina Covaneiro / Isabel Cristina Fernandes / Ana Sofia Gomes 
1525 Contributo para o conhecimento da cosmética islâmica, em Silves, durante a Idade Média Rosa Varela Gomes

1537 Yábura e o seu território - uma análise histórico-arqueológica de Évora entre os séculos VIII-XII José Rui Santos

1547 A encosta sul do Castelo de Palmela - resultados preliminares da escavação arqueológica Luís Filipe Pereira / Michelle Teixeira Santos

1559 A igreja de São Lourenço (Mouraria, Lisboa): um conjunto de silos e de cerâmica medieval islâmica

Andreia Filipa Moreira Rodrigues

1571 O registo material de movimentações populacionais no Médio Tejo, durante os séculos XII-XIII. Dois casos de "sunken featured buildings", nos concelhos de Cartaxo e Torres Novas Marco Liberato / Helena Santos / Nuno Santos

1585 O nordeste transmontano nos alvores da Idade média. Notas para reflexão Ana Maria da Costa Oliveira

1601 Sepulturas escavadas na rocha do Norte de Portugal e do Vale do Douro: primeiros resultados do Projecto SER-NPVD

Mário Jorge Barroca / César Guedes / Andreia Arezes / Ana Maria Oliveira

1619 "Portucalem Castrum Novum" entre o Mediterrâneo e o Atlântico: o estudo dos materiais cerâmicos alto-medievais do arqueossítio da rua de D. Hugo, nํ. 5 (Porto) João Luís Veloso

1627 A Alta Idade Média na fronteira de Lafões: notas preliminares sobre a Arqueologia no Concelho de Vouzela

Manuel Luís Real / Catarina Tente

1641 Um conjunto cerâmico medieval fora de portas: um breve testemunho aveirense Susana Temudo

${ }_{1651}$ Os Lóios do Porto: uma perspetiva integrada no panorama funerário da Baixa Idade Média à Época Moderna em meios urbanos em Portugal

Ana Lema Seabra

1659 O Caminho Português Interior de Santiago como eixo viário na Idade Média Pedro Azevedo

1665 Morfologia Urbana: Um exercício em torno do Castelo de Ourém André Donas-Botto / Jaqueline Pereira

1677 Intervenção arqueológica na Rua Marquês de Pombal/Largo do Espírito Santo (Bucelas, Loures)

Florbela Estêvão / Nathalie Antunes-Ferreira / Dário Ramos Neves / Inês Lisboa

1691 O Cemitério Medieval do Poço do Borratém e a espacialidade funerária na cidade de Lisboa Inês Belém / Vanessa Filipe / Vasco Noronha Vieira / Sónia Ferro / Rodrigo Banha da Silva

1705 Um Espaço Funerário Conventual do séc. XV em Lisboa: o caso do Convento de São Domingos da Cidade Sérgio Pedroso / Sílvia Casimiro / Rodrigo Banha da Silva / Francisca Alves Cardoso

\section{9. Época Moderna e Contemporânea}

1721 Arqueologia Moderna em Portugal: algumas reflexões críticas em torno da quantificação de conjuntos cerâmicos e suas inferências históricas e antropológicas Rodrigo Banha da Silva / André Bargão / Sara da Cruz Ferreira

1733 Faianças de dois contextos entre os finais do século XVI e XVIII do Palácio dos Condes de Penafiel, Lisboa

Martim Lopes / Tomás Mesquita 
1747 Um perfil de consumo do século XVIII na foz do Tejo: O caso do Mercado da Ribeira, Lisboa Sara da Cruz Ferreira / Rodrigo Banha da Silva / André Bargão

1761 Os Cachimbos dos Séculos XVII e XVIII do Palácio Mesquitela e Convento dos Inglesinhos (Lisboa)

Inês Simão / Marina Pinto / João Pimenta / Sara da Cruz Ferreira / André Bargão / Rodrigo Banha da Silva

1775 "Tomar os fumos da erua que chamão em Portugal erua sancta». Estudo de Cachimbos provenientes da Rua do Terreiro do Trigo, Lisboa

Miguel Martins de Sousa / José Pedro Henriques / Vanessa Galiza Filipe

1787 Cachimbos de Barro Caulínitico da Sé da Cidade Velha (República de Cabo Verde)

Rodrigo Banha da Silva / João Pimenta / Clementino Amaro

1801 Algumas considerações sobre espólio não cerâmico recuperado no Largo de Jesus (Lisboa) Carlos Boavida

1815 Adereços de vidro, dos séculos XVI-XVIII, procedentes do antigo Convento de Santana de Lisboa (anéis, braceletes e contas)

Joana Gonçalves / Rosa Varela Gomes / Mário Varela Gomes

1837 Da ostentação, luxo e poder à simplicidade do uso quotidiano: arqueologia e simbologia de joias e adornos da Idade Moderna Portuguesa Jéssica Iglésias

1849 Os amuletos em Portugal - dos objetos às superstições: o coral vermelho Alexandra Vieira

1865 Cerâmicas de Vila Franca de Xira nos séculos XV e XVI Eva Pires

1879 «Não passa por teu o que me pertence». Marcas de individualização associadas a faianças do Convento de Nossa Senhora de Aracoeli, Alcácer do Sal Catarina Parreira / Íris Fragoso / Miguel Martins de Sousa

1891 Cerâmica de Leiria: alguns focos de produção

Jaqueline Pereira / André Donas-Botto

1901 Os Fornos na Rua da Biquinha, em Óbidos Hugo Silva / Filipe Oliveira

1909 A casa de Pêro Fernandes, contador dos contos de D. Manuel I: o sítio arqueológico da Silha do Alferes, Seixal (século XVI) Mariana Nunes Ferreira

1921 O Alto da Vigia (Sintra) e a vigilância e defesa da costa Alexandre Gonçalves / Sandra Santos

1937 O contexto da torre sineira da Igreja de Santa Maria de Loures Paulo Calaveira / Martim Lopes

1949 A Necrópole do Hospital Militar do Castelo de São Jorge e as práticas funerárias na Lisboa de Época Moderna Susana Henriques / Liliana Matias de Carvalho / Ana Amarante / Sofia N. Wasterlain

1963 SAND - Sarilhos Grandes Entre dois Mundos: o adro da Igreja e a Paleobiologia dos ossos humanos recuperados

Paula Alves Pereira / Roger Lee Jesus / Bruno M. Magalhães

1975 Expansão urbana da vila de Cascais no século XVII e XVIII: a intervenção arqueológica na Rua da Vitória no 15 a 17

Tiago Pereira / Vanessa Filipe

1987 Novos dados para o conhecimento do Urbanismo de Faro em época Moderna Ana Rosa 
1995 Um exemplo de Arqueologia Urbana em Alcoutim: o Antigo Edifício dos CTT Marco Fernandes / Marta Dias / Alexandra Gradim / Virgílio Lopes / Susana Gómez Martínez

2007 Palácio dos Ferrazes (Rua das Flores/Rua da Vitória, Porto): a cocheira de Domingos Oliveira Maia

Francisco Raimundo

2021 As muitas vidas de um edifício urbano: História, Arqueologia e Antropologia no antigo Recreatório Paroquial de Penafiel Helena Bernardo / Jorge Sampaio / Marta Borges

2035 O convento de Nossa Senhora da Esperança de Ponta Delgada: o contributo da arqueologia para o conhecimento de um monumento identitário João Gonçalves Araújo / N’Zinga Oliveira

2047 Arqueologia na ilha do Corvo... em busca da capela de Nossa Senhora do Rosário Tânia Manuel Casimiro / José Luís Neto / Luís Borges / Pedro Parreira

2059 Perdidos à vista da Costa. Trabalhos arqueológicos subaquáticos na Barra do Tejo Jorge Freire / José Bettencourt / Augusto Salgado

2071 Arqueologia marítima em Cabo Verde: enquadramento e primeiros resultados do projecto CONCHA

José Bettencourt / Adilson Dias / Carlos Lima / Christelle Chouzenoux / Cristóvão Fonseca / Dúnia Pereira / Gonçalo Lopes / Inês Coelho / Jaylson Monteiro / José Lima / Maria Eugénia Alves / Patrícia Carvalho / Tiago Silva

2085 Trabalhos arqueológicos na Cidade Velha (Ribeira Grande de Santiago, Cabo Verde): reflexões sobre um projecto de investigação e divulgação patrimonial André Teixeira / Jaylson Monteiro / Mariana Mateus / Nireide Tavares / Cristovão Fonseca / Gonçalo C. Lopes / Joana Bento Torres / Dúnia Pereira / André Bargão / Aurélie Mayer / Bruno Zélie / Carlos Lima / Christelle Chouzenoux / Inês Henriques / Inês Pinto Coelho / José Lima / Patrícia Carvalho / Tiago Silva

2103 A antiga fortificação de Quelba / Khor Kalba (E.A.U.). Resultados de quatro campanhas de escavações, problemáticas e perspectivas futuras Rui Carita / Rosa Varela Gomes / Mário Varela Gomes / Kamyar Kamyad

2123 Colónias para homens novos: arqueologia da colonização agrária fascista no noroeste ibérico Xurxo Ayán Vila / José Mạ . Señorán Martín 


\title{
A UTILIZAÇÃO DE QUARTZO DURANTE O PALEOLITICO SUPERIOR NO TERRITÓRIO DOS VALES DOS RIOS VOUGA E CÔA
}

\author{
Cristina Gameiro $^{1}$, Thierry Aubry ${ }^{1,4}$, Bárbara Costa $^{2}$, Sérgio Gomes ${ }^{3}$, Luís Luís ${ }^{1,4}$, Carmen Manzano ${ }^{2}$, \\ André Tomás Santos ${ }^{1,4}$
}

\begin{abstract}
RESUMO
Tradicionalmente o quartzo tem sido apresentado como uma matéria-prima de menor aptidão ao talhe. Porém, o facto de estar disponível, em regiões onde não existe sílex ou silcreto, conduziu à sua frequente exploração, por parte das comunidades humanas que habitaram o território português, durante o Paleolítico. Neste trabalho, apresentamos comparativamente os dados relativos à utilização do quartzo nos sítios do Vale do Côa (Fariseu e Cardina) e do Vale do Vouga (Vau e Rôdo) durante o Gravettense, Magdalenense e Azilense. $\mathrm{O}$ volume de dados sobre as duas áreas em comparação é desigual e dispomos de poucos elementos sobre a tradição técnica e a funcionalidade dos sítios do Vouga. Apesar destas limitações, dispomos já de elementos suficientes para comparar e identificar, nestes sítios arqueológicos situados em distintas regiões, o mesmo esquema conceptual inerente às cadeias operatórias aplicadas aos diferentes tipos de quartzo.

Palavras-chave: Tecnologia lítica, Quartzo, Paleolítico Superior, Vale do Côa, Vale do Vouga.
\end{abstract}

\begin{abstract}
Quartz has traditionally been regarded as a raw material of poor knapping quality. Indeed, the structure of this mineral determines the presence of cleavage planes which generate fractures and influence débitage. The fact that it is naturally available in regions where there is no flint or silcrete, however, resulted in its frequent exploitation by the Palaeolithic human communities that inhabited the Portuguese territory. The present research focuses on comparative data on the use of quartz in the Côa Valley (Fariseu and Cardina) and the Vouga Valley (Vau and Rôdo) sites during the Gravettian, Magdalenian and Azilian. The volume of data on the two areas being compared is uneven and we have little information on the technical tradition and functionality of the Vouga sites. There is, however, enough information to compare and identify, in these archaeological sites located in two different regions, the same conceptual scheme inherent to the chaîne opératoire applied to the different types of quartz.
\end{abstract}

Keywords: Lithic technology, Quartz, Upper Paleolithic, Côa Valley, Vouga Valley.

\section{INTRODUÇÃO}

Tradicionalmente o quartzo tem sido apresentado como uma matéria-prima de menor aptidão ao talhe. Com efeito, a estrutura deste mineral pressupõe a existência de planos de clivagem que originam fraturas e podem condicionar a debitagem (Lombe- ra Hermida, 2008). Porém, o facto de estar disponível, em regiões onde não existe sílex ou silcreto, conduziu à sua frequente exploração, por parte das comunidades humanas que habitaram o território português, durante o Paleolítico. A título de exemplo excecional, refira-se a escolha preferencial desta matéria-prima durante o proto-solutrense da Estre-

\footnotetext{
1. UNIARQ - Centro de Arqueologia da Universidade de Lisboa. Faculdade de Letras de Lisboa. Universidade de Lisboa.

2. Arqueologia e Património Lda.

3. CEAACP - Universidade de Coimbra.

4. Fundação Côa Parque.
} 
madura para a produção de lamelas de dorso marginal. Durante este período, sítios em Rio Maior, situados a menos de $5 \mathrm{~km}$ de fontes de sílex de boa qualidade, apresentam percentagens de quartzo variando entre $22 \%$ e $43 \%$ (Zilhão, Aubry \& Almeida, 1997; Almeida, 2000). É também de salientar que, durante o Paleolítico Superior, em sítios localizados no maciço Hercínico (Bacia do Guadiana, do Vale do Sabor e do Vale do Côa), diferentes variedades de quartzo correspondem ao conjunto da matéria-prima mais utilizada (Aubry, 2009; Almeida, 2013; Gaspar \& alii, 2016; Gameiro \& alii, 2020b). Nos sítios localizados nas Bacias Lusitanianas (Estremadura e Algarve), apesar da disponibilidade do sílex, o quartzo (a par com o quartzito) está sempre presente nas coleções líticas do Paleolítico Superior e, por exemplo, durante o Magdalenense Superior, na Lapa dos Coelhos, a percentagem de quartzo atinge cerca de 36\% (Zilhão, 1997; Gameiro, Aubry \& Almeida, 2013; Bicho $\mathbb{\&}$ alii, 2010). Considerando a recorrência da exploração do quartzo em diferentes regiões, o seu estudo adquire uma especial relevância, viabilizando uma comparação inter-regional que permite alargar a compreensão da variabilidade cultural das comunidades do Paleolítico Superior.

No âmbito deste artigo apresentaremos, comparativamente, os dados relativos à utilização do quartzo nos sítios do Vale do Côa (Fariseu e Cardina) e do Vale do Vouga (Vau e Rôdo). Após uma breve descrição dos contextos de proveniência e dos métodos utilizados exporemos os resultados, articulando os elementos relativos ao aprovisionamento dos vários tipos de quartzo com dados referentes à tecnologia da exploração dos volumes e às modalidades de produção de suportes, com o objectivo de identificar diferenças e semelhanças na utilização dos esquemas conceptuais ao longo do Paleolítico Superior nestas duas regiões do centro de Portugal.

\section{APRESENTAÇÃO DOS CONTEXTOS}

O trabalho de longa duração desenvolvido deste a identificação, em 1995, do primeiro sítio de habitat coevo da realização das gravuras paleolíticas do Vale do Côa, permitiu a identificação de mais de 15 sítios (Figura 1) possibilitando a acumulação de dados sobre o povoamento humano da região e sobre o aprovisionamento de matérias-primas, a produção e a utilização dos artefactos líticos (Aubry, 2009). A aplicação de métodos geoarqueológicos, estabe- lecendo a correlação estratigráfica entre sequências sedimentares (Aubry $\&$ alii, 2010), resultou numa sequência crono-cultural para o Paleolítico Superior regional que tem sido paulatinamente afinada com a obtenção de dados radiométricos (Aubry $\mathbb{8}$ alii, 2020). A identificação das fontes de aprovisionamento das matérias-primas tem sido uma linha de investigação com investimento efetuado não só para o sílex e silcreto alóctones (Aubry \& Mangado Llach, 2006; Aubry, Mangado Llach \& Sampaio, 2009; Aubry, Mangado Llach \& Matias, 2014; Aubry $\&$ alii, 2012, 2016b) mas também com prospeções para matérias-primas locais, permitindo identificar filões hidrotermais e relacionar tipos distintos de quartzo com áreas de aprovisionamento (Aubry $\mathscr{\&}$ alii, 2016a). No âmbito deste artigo, retomamos os dados já publicados (Aubry $\mathbb{Z}$ alii, 2016a) sobre as ocupações do Gravettense, Magdalenense e Azilense dos sítios arqueológicos do Vale do Côa (Olga Grande 4, Olga Grande 14, Cardina, Ínsula II, Quinta da Barca Sul, Fariseu e Olga Grande 6) e completamos informação inédita proveniente dos materiais líticos recuperados na Área Z/A'-6-8 da Cardina. A escavação desta área ocorreu entre 2014 e 2018, tendo-se procedido à publicação da informação relativa à sua implantação e estratigrafia (Aubry \& alii, 2019). Serão efetuadas observações sobre os materiais provenientes dos 12 Níveis Artificiais (NA) da $\mathrm{UE}_{4}$ e dos primeiros 5 NA da UE5. Os primeiros níveis preservaram uma ocupação com estruturas do início do Holocénico (Greenlandian); um fragmento de folha de loureiro (UE4/NA6) e de lamelas de dorso (UE4/NA6 e NA7) permitem, respetivamente, documentar, respectivamente, ocupações do Solutrense médio e do Gravettense final. Uma vez que foram recuperadas lamelas retocadas até ao $\mathrm{NA}_{5} \mathrm{da}$ UE5, está ainda por caracterizar uma ocupação do Paleolítico Superior inicial. O NA1o da UE5 apresenta materiais consentâneos com uma ocupação do Paleolítico Médio (Aubry \& alii, 2019).

Em 2014, no âmbito dos trabalhos arqueológicos desenvolvidos a propósito do impacte patrimonial do Aproveitamento Hidroelétrico de Ribeiradio-Ermida foram identificados e escavados os primeiros sítios (Figura 2) do Vale do Vouga com ocupações do Paleolítico Superior: Rôdo, Vau e Bispeira 8 (Gameiro, \& alii, 2018; Gameiro, \& alii, 2020; Manzano, $\&$ alii, 2020). O estudo dos materiais está em curso, mas os elementos de diagnóstico da indústria lítica, juntamente com as datações de radiocarbono, per- 
mitiram confirmar ocupações humanas no Vau durante o Gravettense médio e talvez durante o Magdalenense final e, no Rôdo e na Bispeira 8, a análise destes elementos, remete para o Magdalenense final e/ou Azilense. O conjunto artefactual pleistocénico recolhido no sítio da Bispeira 8 é reduzido e os elementos em quartzo perfazem um total de três peças (um núcleo e duas lascas), razão pela qual não foi tido em conta nesta análise. Serão apenas considerados os materiais relativos à UEoo5 do Vau e às UEoo3 e UEoo6 do Rôdo. A realização de remontagens líticas entre a UEoo3 e a UEoo5 do Vau confirmou a existência de alterações pós-deposicionais que afetaram estes pacotes sedimentares (Manzano, $\mathbb{\&}$ alii, 2020). Alguns materiais recuperados na UEoo3 podem ser de cronologia pleistocénica e sempre que considerado pertinente serão mencionados.

\section{METODOLOGIA}

Durante o Paleolítico Superior, em regiões desprovidas de sílex, o quartzo constitui a principal fonte de matéria-prima siliciosa. Está disponível, em posição primária ou sub-primária, filões e bandas de quartzo, presentes em granitos e rochas metamórficas, podendo ser utilizado sob a forma de fragmento anguloso ou de cristal (euédrico). Em posição secundária, pode ser encontrado nas formações detríticas continentais, em depósitos fluviais recentes ou em depósitos aluviais antigos. Neste caso, e, tal como os quartzitos, pode ser explorado sob a forma de seixo rolado (Aubry, Mangado Llach \& Matias, 2014; Aubry \& alii, 2016).

O primeiro nível de análise de uma abordagem tecnológica, centrada no conceito de cadeira operatória, é o estudo relativo ao aprovisionamento das matérias-primas. O principal objetivo deste tipo de abordagem é identificar matérias-primas locais, regionais e extra-regionais (Aubry, 2009; Aubry $\&$ alii, 2012, 2016a).

O método desenvolvido no Vale do Côa, para identificação de fontes de aprovisionamento local de quartzo, usa a descrição sistemática e a comparação de amostras geológicas e arqueológicas. A distinção de tipos de quartzo e de fontes disponíveis baseia-se, por enquanto, numa observação macroscópica, mas estão em curso, análises petrográficas e geoquímicas. Para os sítios do Vale do Vouga os tipos de quartzo definidos englobam categorias mais genéricas e, apesar de já terem sido empreendidas algumas prospeções para identificar fontes de matérias-primas, existem, ainda, dúvidas quanto à disponibilidade local de quartzo euédrico.

$\mathrm{Na}$ Figura 3 são apresentados os tipos de quartzo, uma descrição abreviada e os códigos utilizados na análise dos materiais do Vale do Côa, sendo os mesmos tipos referidos no mapa da Figura 1. Para efeitos comparativos entre as duas regiões e por forma a conseguir uma análise diacrónica optámos por aglutinar todos os tipos numa categoria genérica de quartzo.

\section{RESULTADOS}

\subsection{Vale do Côa}

\subsubsection{Cardina}

A Área Z/A'-6-8 da Cardina, cuja escavação decorreu entre 2014 e 2018, permitiu a recolha de 20435 peças líticas. Ao longo da UE4 e dos primeiros quatro níveis artificiais da $\mathrm{UE}_{5}$, a maioria dos materiais líticos é em quartzo e a percentagem desta matériaprima oscila entre os $71 \%$ e os $87 \%$. A percentagem de utilização de sílex, silcreto de silicificações hidrotermais disponíveis regionalmente, varia ao longo da sequência, diminuindo a partir do final do Magdalenense/Azilense, tal como foi já reconhecido noutras áreas deste sítio arqueológico (Aubry \& alii, 2016b). Foram identificados 184 utensílios retocados e, com exceção do nível 11 da UE4, a maioria (65\%) são produzidos em quartzo. $O$ tipo de quartzo mais utilizado é o J9, sendo nesta matéria-prima que foram fabricados a maioria dos utensílios (53) e grande parte dos núcleos (52). No entanto, tendo em conta a fraca aptidão para o talhe, explicável pela existência de clivagens, muitos volumes foram testados e abandonados (26). Ao longo de toda a sequência, a maioria dos utensílios retocados é produzido sobre lasca e são numerosas as peças atípicas, lascas retocadas, entalhes, denticulados e raspadores. As peças esquiroladas são mais frequentes até ao NA6. As raspadeiras em quartzo (6) apenas foram recolhidas no NA5, NA6, NA7, NA9 e NA1o da UE4 e apenas um buril em quartzo foi identificado no NA1o da UE4. Em relação a estratégias de produção de suportes até ao NA9 da UE4 são mais numerosos os núcleos sobre lasca e os de tipo prismático. A estratégia de produção de pequenas lascas ou esquírolas através de debitagem bipolar sobre bigorna acompanha a totalidade da sequência (Figura 4 e Figura $6 n^{\circ}$ 3). No no 2 da Figura 6 podemos observar a utilização 
da aresta de um fragmento anguloso para uma exploração frontal. Um cristal de rocha, com o plano de percussão preparado, foi recolhido no $\mathrm{NA}_{3}$ da $\mathrm{UE}_{4}$ (Figura $6 \mathrm{n}^{\circ} 4$ ).

\subsubsection{Fariseu}

O conjunto lítico recolhido na UE4 do Fariseu, ao longo de três campanhas de escavação (1999, 2005 e 2007), totaliza 6142 peças (Aubry, 2009; Gameiro, 2009, 2012). O quartzo constituí $85 \%$ das matérias-primas utilizadas, revelando uma estratégia de aprovisionamento maioritariamente local, uma vez que apenas $1,4 \%$ das matérias-primas utilizadas são sílex alóctone ou silicificações disponíveis regionalmente. A debitagem é orientada para a obtenção de lascas e lamelas e apenas três lâminas de quartzo foram identificadas de entre os utensílios retocados. A maioria dos utensílios retocados é produzido sobre lasca $(67,5 \%)$ mas a utensilagem lamelar constituí $17 \%$ do total. Este último grupo é composto por lamelas e também por pequenas lascas ou esquírolas retocadas. Cerca de $60 \%$ dos utensílios retocados são fabricados sobre quartzo e $19 \%$ sobre quartzo hialino, confirmando a tendência de utilização maioritária desta matéria-prima local. A utensilagem retocada (114 exemplares) engloba um número considerável de peças de retoque irregular e atípico (43), peças esquiroladas (22), entalhes (15), raspadeiras (8) e denticulados (5). Os utensílios sobre lasca foram produzidos sem preferência por nenhum tipo de quartzo. A única diferença observada é relativa ao tamanho: os utensílios em quartzo J9 apresentam dimensões superiores. A debitagem a partir de seixos de maior dimensão terá sido, possivelmente, efetuada mais perto do local de recolha da matéria-prima, neste caso, mais perto do leito do rio, uma vez que as lascas de grande dimensão terão sido produzidas a partir de núcleos com dimensões, à partida, superiores aos recuperados na área escavada. A utensilagem lamelar foi fabricada quase exclusivamente em quartzo hialino. A análise dos núcleos em quartzo permitiu identificar nove exemplares testados e abandonados (J9); 49 núcleos para produção exclusiva de lascas (sobretudo em J9); sete núcleos lamelares e 17 núcleos para produção de pequenas lascas ou lamelas (Figura 5). Em relação à produção de lascas e ao tipo de volume inicial do quartzo tipo J9, a maioria dos casos, corresponde a um seixo (documentado pela presença de córtex em 32 exemplares); a par dos seixos, foram também explorados alguns fragmentos de quartzo filoniano (8). Em relação ao quartzo tipo Jio, quatro exemplares correspondem a seixos e dois a fragmentos de filão. A maioria dos volumes foi explorado através da criação de uma aresta pela remoção de dois grandes levantamentos criando uma convergência que simultaneamente configura os flancos. Quando a forma natural era favorável, a opção terá sido aproveitar o redondo cortical ou um diedro natural para iniciar a debitagem. Este reduzido investimento na preparação revela-se na existência de um número considerável de plataformas corticais ou lisas. A maioria dos núcleos é unipolar (30) e apresenta uma única zona de debitagem mas, em treze casos foi instalada uma segunda zona de debitagem, observando-se que, em termos de hierarquia, os planos de percussão são sucessivos opostos ou cruzados. Em relação à progressão da debitagem (Pigeot, 1987; Valentin, 1995) na maioria dos volumes foi semi-giratória contínua ou facial. A debitagem de suportes microlíticos (lamelas e pequenas lascas) foi levada a cabo recorrendo ao quartzo de melhor aptidão para o talhe: tipo J1o, tipo J12 e quartzo hialino (J8 e J13). No caso dos dois primeiros tipos de quartzo, a maioria dos volumes iniciais utilizados terá correspondido a blocos angulosos ou a lascas. O diedro natural ou a aresta da lasca terão sido utilizados para iniciada a debitagem. A reduzida dimensão dos volumes não autoriza preparação ou manutenção dos mesmos e a progressão da debitagem é sobretudo frontal, ou seja, utilizada apenas a parte mais estreita dos volumes (Pigeot, 1987; Valentin, 1995). Um dos núcleos utilizado para produzir lamelas apresenta uma morfologia piramidal, resultante de uma progressão da debitagem semi-giratória contínua paralela, com facetagem do plano de percussão. Um outro utiliza uma aresta de lasca para iniciar a debitagem, tendo a exploração sido feita perpendicularmente ao seu eixo, tipo raspadeira carenada (Newcomer \& Hivernel-GuerreI, 1974; Zilhão, 1997; Aubry \&alii, 1998; Gameiro, Aubry \& Almeida, 2013). A exploração bipolar sobre bigorna, por vezes, constitui uma reciclagem de um bloco cujas dimensões não permitem a continuação de outro tipo de estratégia de talhe. Os quatro núcleos lamelares em quartzo hialino (J8 e J13) têm um cristal como volume inicial. Neste caso as faces naturais do cristal são utilizadas para guiar a debitagem. A identificação de um cristal, que acabaria por não ser explorado, com os planos de percussão opostos preparados por micro- 
-facetagem e um ângulo de $45^{\circ}$ sugere-nos que tal seria a única preparação destes núcleos (Figura 6 $\mathrm{n}^{\circ}$ 5). É possível que alguns destes cristais tenham sido debitados apoiados sobre uma bigorna, já que as suas reduzidas dimensões tornam difícil o talhe «à mão livre». Contudo, tal operação seria igualmente possível com recurso a um percutor brando. O talhe experimental efetuado para tentar reproduzir este esquema mostrou que é muito difícil obter suportes regulares e de dimensões estandardizadas recorrendo à percussão bipolar sobre bigorna (Klaric, 2009). As 22 peças esquiroladas incluídas no grupo dos utensílios são peças menos espessas, sem negativos de levantamentos lamelares, mas podem ter sido utilizadas igualmente como peça intermédia e como núcleo (Figura 6 no 7 e 8). A maioria, cerca de catorze peças, pode ser incluída no módulo retangular ou módulo $\mathrm{C}$ de F. Le Brun-Ricalens (2006): dez com dois bordos esquirolados opostos; duas, com quatro bordos esquirolados, revelando um basculamento da direção da percussão.

\subsection{Vale do Vouga}

\subsubsection{Vau}

No conjunto lítico recuperado na UEoo5 do Vau, a maioria das peças (51\%) foi produzida utilizando sílex e silcretos. O quartzo, sob a forma de seixo rolado, de fragmentos provenientes de filão ou sob a forma de cristais está representado por $46 \%$ dos artefactos. Outras rochas de grão grosseiro e o quartzito representam, respetivamente, $2 \%$ e $1 \%$ do total do conjunto. Em quartzo está documentada a produção de lascas, de lamelas e, provavelmente, de pequenas esquírolas (Figura $8 \mathrm{n}^{\circ}$ ). Em geral, os seixos de quartzo foram utilizados para a produção de lascas e apenas um foi utilizado para a obtenção de lamelas. Relativamente ao quartzo filoniano, foi maioritariamente utilizado para produzir lascas $(65 \%$ dos núcleos), mas está igualmente presente a produção de lamelas e de esquírolas. A produção de lascas pode ser classificada como expedita, uma vez que a maioria dos núcleos são considerados "Indeterminável» quanto ao tipo de estratégia (Figura 7). Os planos de percussão são maioritariamente corticais ou constituídos por planos de clivagem próprios desta matéria-prima. A utilização da modalidade sobre bigorna foi igualmente identificada graças à existência de lascas com uma ondulação e indícios tecnológicos, característicos, da utilização deste tipo de estratégia.
As lascas de quartzo foram transformadas em raspadeira, em utensílios do fundo comum ou utilizadas como volume inicial para a produção de lamelas (núcleos tipo raspadeira carenada) (Figura 8 no 1,2 e 4). Apesar da produção lamelar em quartzo estar atestada pela presença de um número muito significativo de núcleos com negativos de levantamentos lamelares, apenas foram identificadas 15 lamelas inteiras e nenhuma delas foi utilizada como suporte para a realização de um utensílio retocado. A análise da indústria em quartzo hialino permitiu documentar a produção de lascas, sendo de destacar que pequenos cristais foram utilizados para debitar lamelas. Nestes casos apenas os planos de percussão são preparados (conferindo-lhe uma inclinação de $45^{\circ}$ ) e as arestas do cristal são utilizadas para guiar os levantamentos lamelares (Figura 8 n 5 e 6). A debitagem bipolar sobre bigorna ou de "tipo peça esquirolada» foi igualmente utilizada no quartzo hialino.

\subsubsection{Rôdo}

Na UEoo3 do Rôdo, o quartzo é a matéria-prima mais explorada ( $74 \%$ do total), no entanto, apenas $21 \%$ dos utensílios foram produzidos nesta matéria-prima: raspadeiras, raspadores e lascas com retoque atípico são os tipos mais comuns. A maioria do quartzo explorado é proveniente de fragmentos de filão e os diedros naturais são, frequentemente, utilizadas para iniciar a debitagem. Esta opção técnica não obriga a uma preparação dos núcleos. De salientar que alguns volumes parecem ter sido apenas testados e abandonados, provavelmente devido à fraca aptidão para o talhe da matéria-prima: diáclases que originam, frequentemente, ressaltos. Para além de uma produção intencional de lascas existiu, igualmente, uma produção de suportes lamelares. As estratégias de produção lamelar identificadas são: debitagem bipolar sobre bigorna (Figura ํㅡ 8, 9 e 12); a debitagem sobre aresta de lasca e um núcleo piramidal, que revela uma exploração giratória de toda a superfície do volume (Figura $8 \mathrm{n}^{\mathrm{o}}$ 11). A utilização da modalidade sobre bigorna pode indicar, igualmente, uma intenção de produzir pequenas lascas (Figura 8 no 10 ). Para o quartzo hialino foram utilizadas estratégias de debitagem mais elaboradas. As lascas ocorrem em número superior, verificando-se um comprimento médio de $1,5 \mathrm{~cm}$, que documenta a produção intencional de pequenas lascas/ esquírolas sobretudo recorrendo à debitagem bipolar sobre bigorna. De um total de 72 lamelas iden- 
tificadas, apenas 20 estão completas e, apenas um exemplar foi alvo de retoque. No que diz respeito a utensílios, regista-se a presença de lascas retocadas, raspadores, raspadeiras e uma lamela com retoque marginal. Na UEoo6, com exceção de alguns macro-utensílios, a utensilagem em quartzo é efetuada sobre lasca: dominam os utensílios de fundo comum (raspadores e entalhes), as raspadeiras (Figura $8 \mathrm{n}^{\circ}$ 8) e as lascas ou fragmentos com retoque irregular. Alguns núcleos foram utilizados para a produção de pequenas lascas, sobretudo utilizando a debitagem bipolar sobre bigorna (Figura $8 \mathrm{n}^{\circ}$ 7). A debitagem de suportes lamelares está documentada mas apenas dois exemplares estão retocados: uma lamela de dorso e uma lamela retocada. O quartzo hialino foi maioritariamente utilizado para a debitagem de suportes lamelares. Foram recuperadas 78 lamelas; no entanto, apenas 17 peças estão inteiras. Este facto poderá ter relação com a ocorrência de fraturas durante a produção por utilização de debitagem bipolar. As 141 lascas identificadas são todas de reduzidas dimensões: $1,3 \mathrm{~cm}$ de comprimento em média. Apenas três núcleos produziram exclusivamente lascas e dois produziram lascas e lamelas.

\section{DISCUSSÃO}

Com exceção das ocupações do Gravettense médio do Vau (UEoo5), onde a percentagem de quartzo não ultrapassa os $46 \%$, e da Olga Grande 14 (UE3), onde num pequeno conjunto artefactual, o quartzo representa $39 \%$, os restantes conjuntos do Paleolítico Superior, tanto no Vale do Côa como no Vale do Vouga, são maioritariamente compostos por vários tipos de quartzo (Tabela 1).

A utilização maioritária de quartzo dá origem a coleções líticas de aspeto fruste, com pouca produção laminar e lamelar e com grande quantidade de restos de talhe e esquírolas. Aliás, a elevada fragmentação do quartzo, pode aumentar a proporção desta matéria-prima (Bracco \& Morel, 1998). A elevada percentagem de utensilagem comum é outra das características do uso de matérias-primas locais de menor aptidão ao talhe. Apesar da utensilagem lamelar estar sempre presente, nem sempre o quartzo é a matéria-prima escolhida para o fabrico deste tipo de peças. Aliás, frequentemente, sílex e silcreto são escolhas preferenciais (Aubry \& alii, 2016a; Gameiro, Aubry \& Almeida, 2013). Por esta razão, optámos por enfatizar as estratégias de debitagem para pro- dução de suportes, observando e comparando diacronicamente a utilização do quartzo.

Nas coleções líticas recuperadas nos sítios arqueológicos do Rôdo e Vau (Vouga) e da Cardina e Fariseu (Côa) foram identificados núcleos de quartzo prismáticos ou sobre lasca talhados à mão livre/sem apoio. Nas duas regiões é percetível um domínio das técnicas, um savoir-faire implícito à utilização e rentabilização dos recursos litológicos regionais que é levado ao seu expoente máximo com a debitagem de suportes lamelares a partir de cristais naturais. No entanto, critérios economicistas terão conduzido à utilização de metodologias mais expeditas, como a debitagem de pequenas lascas ou esquírolas através de debitagem bipolar sobre bigorna. $\mathrm{Na}$ ausência dos núcleos é, por vezes, possível antever a aplicação destas estratégias de talhe pela existência de lascas, fragmentos e restos talhe característicos. Atribuir às peças esquiroladas uma utilização como núcleo ou utensílio é uma problemática inerente a deste tipo de colecções (Shott, 1999; Lucas \& Hays, 2004; Le Brun Ricalens, 2006; Almeida, 2007; Hays \& Lucas, 2009; Gameiro, 2009; Peña, 2015; Pargeter \& Peña, 2017) e tem sido opção classificar como utensílios as peças menos espessas, sem vestígios de preparação de planos de percussão e ângulos mais fechados, não esquecendo, contudo, que algumas peças podem ter conhecido uma dupla utilização. Em alguns casos, esta estratégia, parece ter sido utilizada como reciclagem de núcleos, cujas reduzidas dimensões tornavam difícil a aplicação de outro tipo de debitagem. No entanto, esta não parece ter sido regra única. No Fariseu está documentada uma produção deliberada de pequenos suportes através de debitagem bipolar sobre bigorna. A transformação pelo retoque de suportes com dimensões $<1 \mathrm{~cm}$ patenteia uma simbiose exemplar entre economia e oportunismo (Aubry \& alii, 1998; Gameiro, 2009; Klaric, 2009). A quase ausência de utensilagem lamelar em quartzo nos sítios do Vouga, levanta outras hipóteses: produção e exportação de suportes a retocar e utilizar noutro local? Com os dados disponíveis não é possível responder a esta questão.

Na Foz do Medal, no Vale do Sabor, a utilização das diversas variedades de quartzo é sempre predominante ao longo das ocupações do Paleolítico Superior. A percentagem de quartzo diminui durante o Solutrense (43\%) mas é elevada durante o Gravettense $(83 \%)$ e Magdalenense (65\%). Relativamente às modalidades de produção de suportes, a utiliza- 
ção de cristais e a debitagem bipolar sobre bigorna, foram igualmente identificadas nos níveis do Gravettense, Solutrense e Magdalenense. Foi igualmente documentada uma produção intencional de lascas de pequena dimensão e de lamelas, estas últimas, produzidas preferencialmente em quartzo hialino e noutras variedades de quartzo de melhor aptidão para o talhe e silicificações locais e alóctones, utilizando núcleos prismáticos, núcleos sobre lasca e debitagem bipolar sobre bigorna (Gaspar \& alii, 2016). No Vale do Guadiana, o contexto do Magdalenense final e/ou Azilense da Malhada do Mercador, apresenta uma percentagem de quartzo na ordem dos $45 \%$ e a debitagem bipolar sobre bigorna também foi utilizada com frequência (Almeida, 2013; Gameiro, Aubry \& Almeida, 2013).

No Algarve, nos níveis do Gravettense, Solutrense e Magdalense de Vale Boi o quartzo apresenta-se como a segunda matéria-prima melhor representada (depois do sílex) e refere-se a presença de peças esquiroladas em quartzo no Gravettense e no Solutrense (Bicho $\&$ alii, 2010; Horta, Cascalheira \& Bicho, 2019).

\section{CONSIDERAÇÕES FINAIS}

A maioria das variedades de quartzo utilizadas nos sítios do Vale do Côa estão disponíveis em filões ou em depósitos de vertente próximos dos sítios (Aubry $\&$ alii, 2016a). No entanto, há sempre utilização de outras matérias-primas disponíveis regionalmente (20-40km), demonstrando o conhecimento do ambiente litológico regional (Aubry \& alii, 2016b).

Durante o Gravettense médio a percentagem de utilização de matérias-primas locais era mais reduzida do que nos períodos subsequentes e apresenta valores semelhantes no Vale do Vouga e no Vale do Côa (Figura 1o). A utilização maioritária de matérias-primas alóctones de boa qualidade tem sido interpretada como uma característica das "fases pioneiras de ocupação" (Mevel, 2013). Numa fase de colonização do território não existe um conhecimento da litologia regional e, é expectável, maior quantidade de matéria-prima transportada. Numa fase posterior, com a continuidade das deslocações no mesmo território, com um conhecimento consolidado sobre as fontes de matéria-prima locais, o transporte de matérias-primas exóticas tende a diminuir. Tal comportamento foi identificado nas primeiras fases de ocupação de territórios da América do Norte
(Kelly \& Todd, 1988), durante a transição Pleistocénico-Holocénico no Reino Unido (Graf \& Goebel, 2003) e nos Alpes durante o Magdalenense e Azilense (Mevel, 2013).

No Vale do Côa, estão sempre presentes matérias-primas alóctones, o seu uso é quase sempre circunscrito à utensilagem lamelar e entre o Gravettense e o Azilense parece haver uma contração da área de aprovisionamento (Aubry $\&$ alii, 2016b).

A debitagem bipolar sobre bigorna, para produção de pequenas lascas ou esquírolas, é utilizada nestas duas regiões desde o Gravettense (Aubry $\&$ alii, 1998; 2016a; Klaric, 2009; Gameiro \& alii, 2018;) continuando presente no Magdalenense e Azilense (Gameiro, 2009; 2012; Aubry \& alii, 2016; Gameiro \& Aubry, no prelo; Gameiro \& alii, 2020a). Esta estratégia tem sido interpretada como uma tentativa de rentabilizar a matéria-prima, sendo que a sua utilização durante uma longa diacronia não permite que seja utilizada como um indicador cronológico. A utilização de cristais de quartzo hialino, utilizando as faces naturais dos cristais, para a produção de suportes lamelares está igualmente documentada nestas duas regiões e encontra paralelos na região vizinha do Vale do Sabor (Gaspar \& alii, 2016).

No que concerne à transformação dos suportes produzidos apenas dispomos de elementos para comparar os utensílios sobre lasca, uma vez que são raras as armaduras em quartzo recolhidas nos sítios do Vouga. Durante todas as fases do Paleolítico Superior, o quartzo disponível localmente é sobretudo utilizado nos utensílios sobre lasca, evidenciando uma lógica de produção, consumo e descarte (Aubry \& alii, 2016a; Gameiro \& Aubry, no prelo).

$\mathrm{O}$ volume de dados sobre as duas áreas em comparação é desigual, uma vez que dispomos de poucos elementos sobre o aprovisionamento regional de matérias primas, a tradição técnica e a funcionalidade dos sítios do Vouga. Contudo, a comparação dos resultados obtidos no âmbito do estudo dos diferentes conjuntos líticos apresentados, permite-nos reconhecer que, apesar das especificidades de cada sítio arqueológico, é possível reconhecer o mesmo esquema conceptual inerente às cadeias operatórias aplicadas aos diferentes tipos de quartzo.

Entre o Gravettense e o Tardiglaciar, no Vale do Côa, está documentada a utilização dos mesmos tipos de sílex, silcreto e silicificações hidrotermais disponíveis na Meseta espanhola e na Estremadura portuguesa. A maioria destas matérias-primas foi identifi- 
cada nos sítios paleolíticos do Vale do Vouga, região situada a meio caminho entre o Vale do Côa e as fontes de sílex da Estremadura (Aubry \& alii, 2016b; Gameiro \& Aubry, no prelo). Interpretando os sítios de arte Paleolítica do Vale do Côa como um local de agregação (Santos, 2019), podemos antever a mobilidade dos grupos humanos entre estas duas regiões, separadas por mais de $15 \mathrm{okm}$, possibilitando a troca de matérias-primas líticas com diversas proveniências e a difusão do savoir faire relativo à produção de artefactos líticos.

\section{AGRADECIMENTOS}

A investigação que serviu de base a este artigo foi financiada por fundos nacionais através da FCT Fundação para a Ciência e a Tecnologia, I.P., no âmbito do projeto O Paleolítico Superior e a Arqueologia Preventiva em Portugal: desafios e oportunidades (PTDC/HAR-ARQ/30779/2017) e do projecto $A$ transição do Neandertal para o Homem Anatomicamente Moderno no Vale do Côa: ambientes, simbolismos e redes sociais (PTDC/EPH-ARQ/o326/2014).

\section{BIBLIOGRAFIA}

ALMEIDA, Francisco (200o) - The terminal Gravettian of Portuguese Estremadura. Dallas: Southern Methodist University (Dallas, EUA). [Tese de doutoramento policopiada].

ALMEIDA, Francisco (2007) - The production of lithic barbs in the context of the Core Vs Tool dichotomy: the portuguese Upper Paleolithic case. In McPHERRON, Shannon (ed.) - Tools versus Cores: Alternative Approaches to Stone Tool Analysis, Cambridge Scholars Publishing, Newcastle, pp.127-142.

ALMEIDA, Francisco (dir.) (2013) - Testemunhos do Paleolítico no Regolfo de Alqueva. Resultados do Bloco 1 do Plano de Minimização de impactes sobre o Património Arqueológico. Beja:EDIA.

AUBRY, Thierry (ed.) (2009) - 200 séculos da História do Vale do Côa: incursões na vida quotidiana dos caçadores-artistas do Paleolítico. Lisboa:IGESPAR (Trabalhos de Arqueologia 52).

AUBRY, Thierry, BARBOSA, Fernando, LUís, Luís, SANTOS, André Tomás, SILVESTRE, Marcelo, (2016a) Quartz use in the absence of flint: Middle and Upper Palaeolithic raw material economy in the Côa Valley (Northeastern Portugal). Quaternary International 424: 113-129 doi:10.1016/j.quaint.2015.11.067

AUBRY, Thierry; BARBOSA, Fernando; GAMEIRO, Cristina; LUÍS, Luís; SANTOS, André; SILVESTRE, Marcelo (2019) - Cardina I-Salto do Boi: cinco metros de arqui- vo da ocupação paleolítica no Vale do Côa. Côa Visão 21, pp. 63-74.

AUBRY, Thierry; DIMUCCIO, Luca; ALMEIDA, Miguel; NEVES, Maria; ANGELUCCI, Diego; CUNHA, Lúcio (2010) - Palaeoenvironmental forcing during the Middle-Upper Palaeolithic transition in central-wertern Portugal. Quaternary Research. Doi:101016/j.yqres.2010.11.002.

AUBRY, Thierry; DIMUCCIO, Luca; BARBOSA, Fernando; LUÍS, Luís; SANTOS, André; SILVESTRE, Marcelo; HONSEN, Kristina; RADES, Eike; AUTZEN, Martin; MURRAY, Andrew (2020) - Timing of the Middle-to-Upper Palaeolithic transition in the Iberian inland (CardinaSalto do Boi, Côa Valley, Portugal). Quaternary Research 1-21. doi:10.1017/qua.2020.43

AUBRY, Thierry; GAMEIRO, Cristina; MANGADO LLACH; Javier; LUÍS, Luís; MATIAS; Henrique; PEREIRO, Tiago (2016b) - Upper Palaeolithic lithic raw material sourcing in Central and Northern Portugal as an aid to reconstructing hunter-gatherer societies. Journal of Lithic Studies 3(2). doi:10.2218/jls.v3i2.1436

AUBRY, Thierry; LUÍs, Luís; MANGADO LLACH, Javier; MATIAS, Henrique (2012) - We will be known by the tracks we leave behind: Exotic lithic raw materials, mobility and social networking among the Côa Valley foragers (Portugal). Journal of Anthropological Archaeology 31(4). pp. 528-550.

AUBRY, Thierry; MANGADO LLACH, Javier; MATIAS, Henrique (2014) - Matérias-primas das ferramentas em pedra lascada da Pré-história do Centro e Nordeste de Portugal. In DINIS, P.; GOMES, Alberto.; MONTEIRO-RODRIGUES, Sérgio - Proveniências de Materiais Geológicos, Associação Portuguesa para o Estudo do Quaternário. pp. 165-192.

AUBRY, Thierry \& MANGADO LLACH, Javier (2006) The Côa Valley (Portugal). From lithic raw materials characterization to the reconstruction of settlement patterns during the Upper Palaeolithic. In: BRESSY, C., BURKE, A.; CHALARD, P.; MARTIN, H. dir.-Notions de territoire et de mobilité. Exemples de l'Europe et des premières nations en Amérique du Nord avant le contact européen. Actes de sessions présentées au $X^{\circ}$ congrès annuel de l'E.A.A. (Lyon, 8-11-09-2004). Liège: ERAUL (116), pp. 41-49.

AUBRY,Thierry;MANGADOLLACH,Javier;SAMPAIO, Jorge (2009) - Estudo do aprovisionamento em matérias-primas. In AUBRY, Thierry (ed.) - 200 séculos da História do Vale do Côa: incursões na vida quotidiana dos caçadores-artistas do Paleolítico, Lisboa:IGESPAR (Trabalhos de Arqueologia 52), pp. 131-169.

AUBRY, Thierry; ZILHÃO, João; ALMEIDA, Francisco; FONTUGNE, Miguel (1998) - Production d'armatures microlithiques pendant le Paléolithique supérieur et le Mésolithique au Portugal. Actas del II Congresso de Arqueologia Peninsular, Zamora, pp. 259-272. 
BICHO, Nuno; MANNE, Tiina; MENDONÇA, Carolina; ÉVORA, Marina; GIBAJA, Juan; PEREIRA, Telmo (2010) - O Paleolitico superior do sudoeste da Península Ibérica: o caso do Algarve. In MANGADO LLACH, Javier (dir.) El Paleolítico superior peninsular. Novedades del siglo XXI. Universidad de Barcelona. Barcelona, pp. 219-238.

BRACCO, Jean-Pierre; MOREL, Philipe (1998) - Outillage en quartz et boucherie au Paléolithique supérieur: quelques observations expérimentales. In Économie Préhistorique: les comportements de subsistance au Paléolithique. XVIIIe Rencontres internationales d'Archéologie et d'Histoire d'Antibes. Sophia Antipolis: Éditions APDCA, pp. 387-395.

LOMBERA HERMIDA, Arturo de (2008) - Quartz morphostructural groups and their mechanical implications. Museologia Scientifica e Naturalista. Annali dell'Università degli Studi di Ferrara. 2008: 101-105.

GAMEIRO, Cristina (2009) - Utensílios e suportes microlíticos do Magdalenense final no Vale do Côa: o exemplo da U.E. 4 do Fariseu. In AUBRY, T. (ed.), 200 séculos da História do Vale do Côa: incursões na vida quotidiana dos caçadores-artistas do Paleolítico. Lisboa: IGESPAR (Trabalhos de Arqueologia, vol. 52), pp. 256-268.

GAMEIRO, Cristina (2012) - La variabilité régionale des industries lithiques de la fin du Paléolithique Supérieur au Portugal. [Tese de Doutoramento, Université de Paris IPanthéon-Sorbonne. Exemplar policopiado].

GAMEIRO, Cristina; AUBRY, Thierry (no prelo) - Rôdo, Vau e Bispeira 8: integração crono-cultural, enquadramento regional e contextualização no quadro do Paleolítico Superior Peninsular. In G. Branco, P. Abranches e F. Telles (eds), Monografia dos trabalhos de minimização do impacte patrimonial do Aproveitamento Hidroelétrico de Ribeiradio-Ermida, pp.604-671.

GAMEIRO, Cristina; AUBRY, Thierry; ALMEIDA, Francisco (2013) - A variabilidade regional das indústrias líticas do final do Paleolítico Superior em Portugal. Arqueologia em Portugal - 150 anos actas do Congresso da Associação dos Arqueólogos Portugueses, Lisboa, Associação dos Arqueólogos Portugueses, pp. 277-287.

GAMEIRO, Cristina; AUBRY, Thierry; ALMEIDA, Francisco; DIMUCCIO, Luca; GABRIEL, Sónia; GASPAR, Rita; GOMES, Sérgio; FÁBREGAS VALCARCE, Ramon; FIGUEIREDO, Sofia; MANZANO, Carmen; MARREIROS, João; OLIVEIRA, Claúdia; SANTOS, André; SILVA, Maria; TERESO, João; XAVIER, Pedro (2020a) - Archaeology of the Pleistocene-Holocene transition in Portugal: Synthesis and prospects. Quaternary International https://doi.org/10.1016/j.quaint.2020.03.018

GAMEIRO, Cristina; GOMES, Sérgio; MANZANO, Carmen; COSTA, Bárbara; AMEIJENDA, A.; OLIVEIRA, Lurdes, MONTEIRO-RODRIGUES, Sérgio, GOMES, Alberto; OLIVEIRA, Cláudia; TERESO, J.; MATIAS, H.; AUBRY, T.
(2018) - The Pleistocene-Holocene transition: new data from the sites of Rôdo, Vau and Bispeira 8 (Vouga valley, Portugal). Poster apresentado no $8^{\text {th }}$ Annual Meeting of the European Society for the study of Human Evolution, Faro, 13-15 setembro de 2018.

GAMEIRO, Cristina; MANZANO, Carmen; COSTA, Bárbara; AMEIJENDA; Alicia; GOMES, Sérgio; MONTEIRO-RODRIGUES, Sérgio; GOMES, Alberto; AUBRY, Thierry; MATIAS, Henrique (2020b) - Contributos para a caracterização do período tardiglaciar no Médio Vouga: a indústria lítica do Rôdo, Vau e Bispeira 8, Arqueologia \& História Revista da Associação dos Arqueólogos Portugueses, Vol. 70, Ano associativo 2018, Associação dos Arqueólogos Portugueses, Lisboa, pp. 149-171.

GASPAR, Rita; FERREIRA, João; CARRONDO, Joana; SILVA, Maria João (2016) - The use of quartz during the Upper Paleolithic and Early Mesolithic in Sabor valley (NW Iberia): The Foz do Medal case. Quaternary International, 424, pp. 98-112.

GRAF, Kelly \& GOEBEL, Frank (2009) - Upper Palaeolithic toolstone procurement and selection across Beringia, in ADAMS, B. \& BLADES, B.S. (ed.) Lithic material and Palaeolithic societies: Chichester: Wiley-Blackwell, pp. 54-77.

HAYS, Maureen; LUCAS, Geraldine (2007) - Pieces esquillees from Le Flageolet I (Dordogne, France): Tools or Cores? In McPHERRON, Shannon (ed.) - Tools versus Cores: Alternative Approaches to Stone Tool Analysis, Cambridge Scholars Publishing, Newcastle, pp. 107-126.

HORTA, Pedro; CASCALHEIRA, João; BICHO, Nuno (2019) - The role of lithic bipolar technology in Western Iberia's Upper Paleolithic: the case of Vale Boi (Southern Portugal). Journal of Paleolithic Archaeology, 2 (2), pp. 134-159.

KELLY, Robert \& TODD, Laurence (1988) - Coming into the country: early Paleoindian hunting and mobility. American Antiquity. 53(2). pp. 31-44.

KLARIC, Laurent (2009) - Les systèmes de production de supports d'armatures et leur place dans la gestion de ressources lithiques: une voie privilégiée pour la compréhension des sociétés gravettiennes de la Vallée du Côa. In AUBRY, T. ed. - 200 séculos da História do Vale do Côa: incursões na vida quotidiana dos caçadores-artistas do Paleolítico. Lisboa: IGESPAR (Trabalhos de Arqueologia 52), pp. 247-256.

LE BRUN-RICALENS, Foni (2006) - Les pièces esquillées: état des connaissances après un siècle de reconnaissance. Paleo. 18, pp.95-114.

LUCAS, Géraldine; HAYS, Maureen (2004) - Les pièces esquillées du site paléolithique du Flageolet I (Dordogne): outils ou nucléus? In Approches fonctionnelles en Préhistoire. XXV ${ }^{\text {ème }}$ Congrès Préhistorique de France. Paris. pp. 107-120.

MANZANO, Carmen; GAMEIRO, Cristina; GOMES, Sérgio; COSTA, Bárbara; AMEIJENDA; Alicia; MONTEIRO-RODRIGUES, Sérgio; GOMES, Alberto; AUBRY, Thierry; 
MATIAS, Henrique (2020) - A indústria lítica do Gravettense Médio do Vau (Médio Vouga): apresentação de dados preliminares, Arqueologia 8 História - Revista da Associação dos Arqueólogos Portugueses, Vol. 70, Ano associativo 2018, Associação dos Arqueólogos Portugueses, Lisboa, pp. 117-133.

MEVEL, Ludovic (2013) - Magdalenian pioneers in the northern French Alps, 17 ooo cal BP. Antiquity. 87, pp. 384-404.

NEWCOMER, Mark; HIVERNEL-GUERRE, Françoise (1974) - Nucléus sur éclat: technologie et utilisation par différentes cultures préhistoriques. Bulletin de la Société Préhistorique Française. 71, pp. 119-127.

PARGETER, Justin; PEÑA, Paloma de la (2017) - Milky Quartz Bipolar Reduction and Lithic Miniaturization: Experimental Results and Archaeological Implications. Journal of Field Archaeology. Vol.42(6), pp. 551-565.

PEÑA, Paloma de la (2015) - The interpretation of bipolar knapping in African stone age studies. Current Anthropology. Vol. 56(6), pp. 911-923.

PIGEOT, Nicole (1987) - Magdaléniens d'Etiolles. Économie de débitage et organisation sociale. Éditions du CNRS, Paris.
SANTOS, André Tomás (2019) - A arte paleolítica ao ar livre da bacia do Douro a margem direita do Tejo: uma visão de conjunto. Associação dos Arqueólogos Portugueses: Lisboa.

SHOTT, Michael (1999) - On bipolar reduction and splintered pieces. North American Archaeologist. Vol. 20(03), pp. $217-238$.

VALENTIN, Boris (1995) - Les groupes humains et leurs traditions au tardiglaciaire dans le bassin parisien. Université de Paris I, Panthéon-Sorbonne [Tese de doutoramento policopiada].

ZILHÃO, João (1997) - O Paleolitico Superior da Estremadura Portuguesa. Ed. Colibri, Lisboa.

ZILHÃO, João; AUBRY, Thierry; ALMEIDA, Francisco (1997) - L'utilisation du quartz pendant la transition Gravettien-Solutréen au Portugal. Préhistoire et Anthropologie Méditerranéennes. 6, pp. 289-303.

\begin{tabular}{|c|c|c|c|c|c|c|c|c|c|c|}
\hline \multicolumn{11}{|l|}{ Vale do Vouga } \\
\hline \multirow[b]{2}{*}{ Atribuição Cultural } & \multirow{2}{*}{$\begin{array}{l}\text { Proveniência } \\
\text { (UE/sítio } \\
\text { arqueológico) }\end{array}$} & \multirow{2}{*}{$\begin{array}{l}\text { Total } \\
\left(\mathrm{N}^{\mathrm{o}}\right)\end{array}$} & \multicolumn{2}{|c|}{ Quartzo } & \multicolumn{2}{|c|}{ Quartzito } & \multicolumn{2}{|c|}{ Silicificações* } & \multicolumn{2}{|c|}{ Outras** } \\
\hline & & & № & $\%$ & № & $\%$ & № & $\%$ & № & $\%$ \\
\hline Gravettense Médio & UEoo5 Vau & 4053 & 1865 & 46 & 64 & 1 & 2051 & 51 & 73 & 2 \\
\hline Magdalenense Final & UEo 3 Rôdo & 21343 & 14970 & 74 & 1459 & 5 & 1765 & 11 & 3144 & 10 \\
\hline Azilense (?) & UEoo6 Rôdo & 7864 & 6205 & 81 & 325 & 5 & 625 & 6 & 709 & 8 \\
\hline \multicolumn{11}{|l|}{ Vale do Côa } \\
\hline \multirow{3}{*}{ Gravettense Médio } & $\mathrm{UE}_{3}$ Olga Grande 4 & 9778 & 8525 & 87 & 971 & 10 & 236 & 2 & 46 & 0,5 \\
\hline & $\mathrm{UE}_{3}$ Olga Grande 14 & 364 & 141 & 39 & 174 & 48 & 32 & 9 & 17 & 5 \\
\hline & UE4b Cardina & 20259 & 10754 & 53 & 8608 & 42 & 839 & 4 & 58 & 0,3 \\
\hline \multirow{2}{*}{ Gravettense Final } & UE4.10 Cardina & 28213 & 15381 & 55 & 11875 & 42 & 948 & 3 & 9 & 0,0 \\
\hline & UE2 Ínsula & 1267 & 978 & 77 & 242 & 19 & 45 & 4 & 2 & 0,2 \\
\hline Proto-Solutrense & UE2c Olga Grande 14 & 1592 & 1408 & 88 & 71 & 4 & 63 & 4 & 50 & 3 \\
\hline Magdalenense Final & UE4.2-4 Cardina & 9534 & 7478 & 78 & 1452 & 15 & 279 & 3 & 325 & 3 \\
\hline \multirow{3}{*}{ Azilense } & UE4.1 Cardina & 2145 & 1770 & 83 & 284 & 13 & 44 & 2 & 47 & 2 \\
\hline & UE3 Quinta da Barca & 996 & 790 & 79 & 118 & 12 & 77 & 8 & 11 & 1 \\
\hline & $\mathrm{UE}_{4}$ Fariseu & 6142 & 5221 & 85 & 830 & 14 & 84 & 1,4 & 7 & 0,1 \\
\hline
\end{tabular}

Tabela 1 - Inventário geral por matéria-prima das principais ocupações do Paleolítico Superior do Vale do Côa e do Vale do Vouga. * Incluí sílex, silcreto e silicificações hidrotermais. ${ }^{* *}$ Inclui matérias-primas classificadas como anfibolito, micro-gabro, lidite e riólito. 


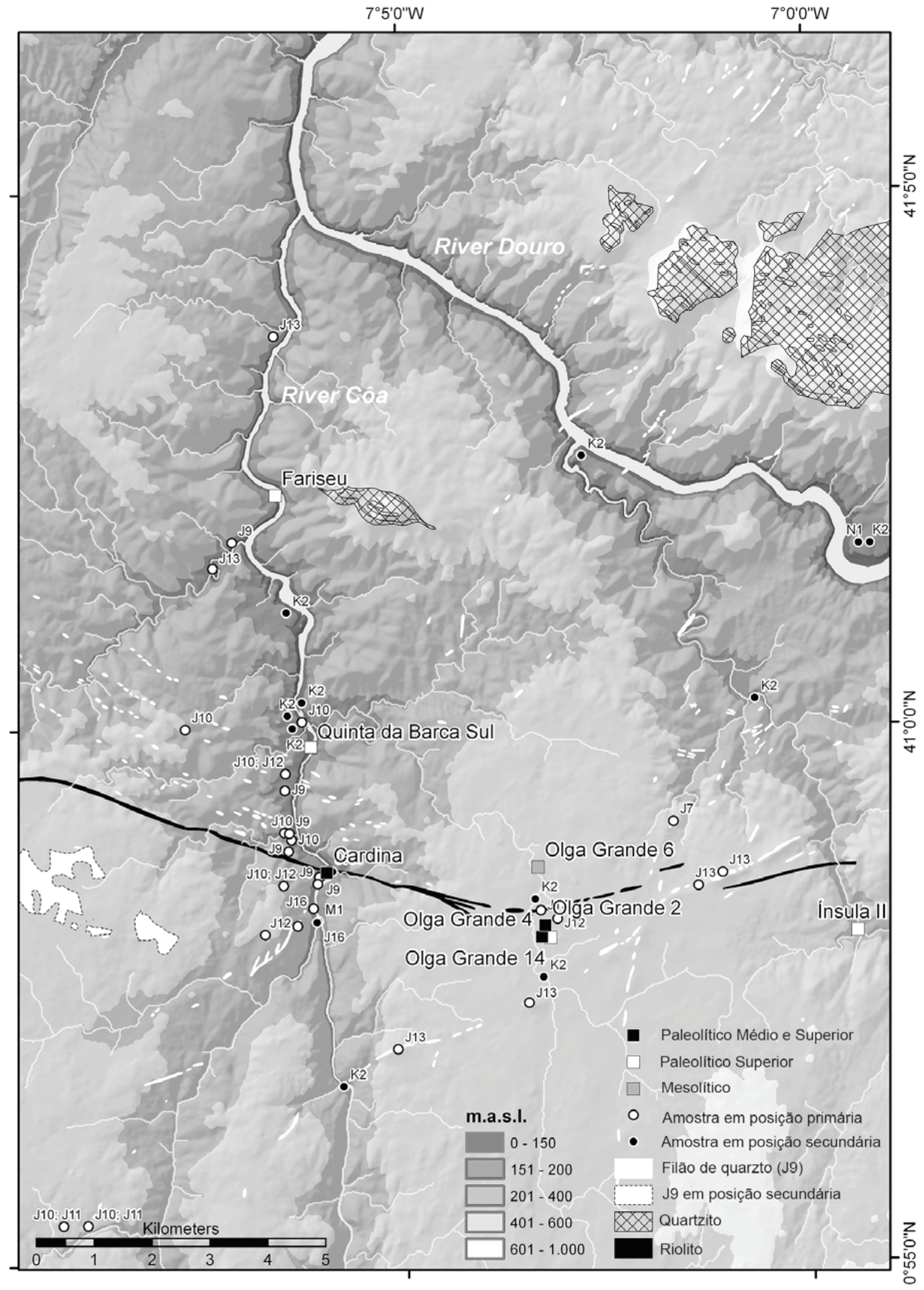

Figura 1 - Os sítios do Paleolítico e Mesolítico do Vale do Côa e localização de matérias-primas locais. Mapa adaptado de Aubry \& alii, 2016a. 

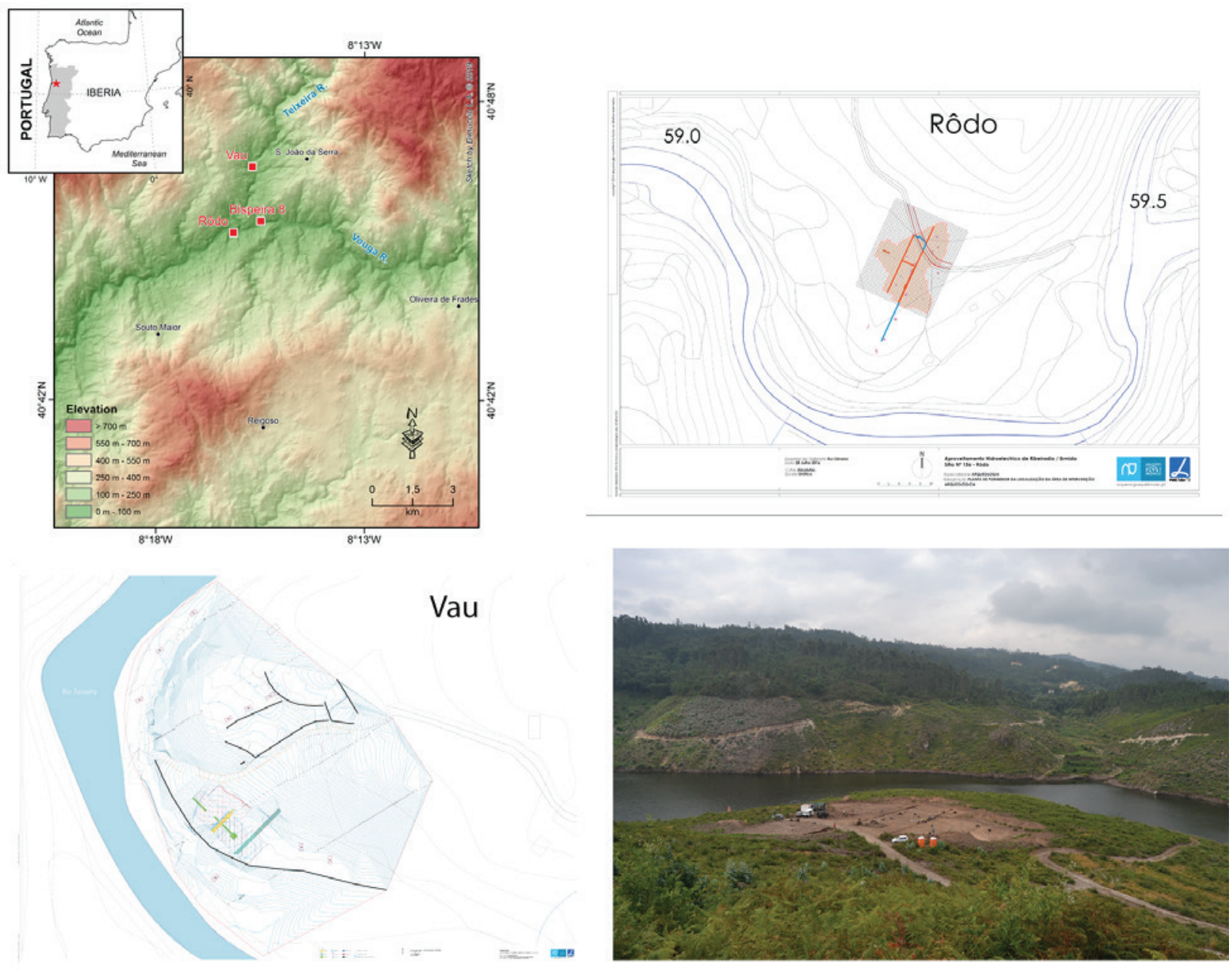

Figura 2 - Localização dos sítios paleolíticos do Vale do Vouga (mapa por L. Dimuccio), implantação das áreas escavadas e fotografia do sítio arqueológico Rôdo durante os trabalhos de escavação (Arqueologia \& Património).

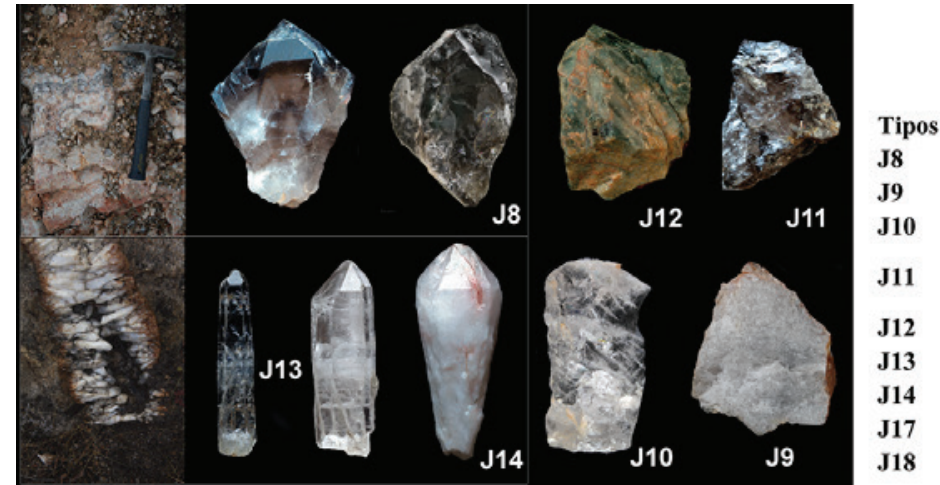

$\begin{array}{ccc}\text { Vale do Côa } & \text { I Vale do Vouga } \\ \text { Descrição } & \text { I } & \\ \text { Quartzo fumado euédrico } & \text { I Quartzo fumado } \\ \text { Quartzo leitoso e cinzento anédrico } & \text { I Quartzo filão e de } \\ \text { Quartzo translúcido e branco anédrico } & \text { I } & \text { seixo } \\ \text { Quartzo bandeado translúcido e branco } & \text { anédrico } & \text { Quartzo cinzento } \\ \text { Quartzo cinzento bandeado anédrico } & \text { I Quartzo hialino } \\ \text { Quartzo translúcido e branco euédrico } & \text { I Quartzo leitoso euédrico } & \text { Q } \\ \text { Quartzo fumado anédrico } & \text { Quartzo rosa anédrico } & \end{array}$

Figura 3-Amostras de quartzo recolhidas durante as prospeções no Vale do Côa. Descrição abreviada dos tipos de quartzo identificados com menção ao código utilizado no Vale do Côa. Para informação sobre a proveniência destas matérias primas consultar o mapa da Figura 1. Adaptado de Aubry \& alii, 2016a. As categorias utilizadas para a análise dos materiais do Vale do Vouga são, de momento, mais genéricas. 
Núcleos em quartzo

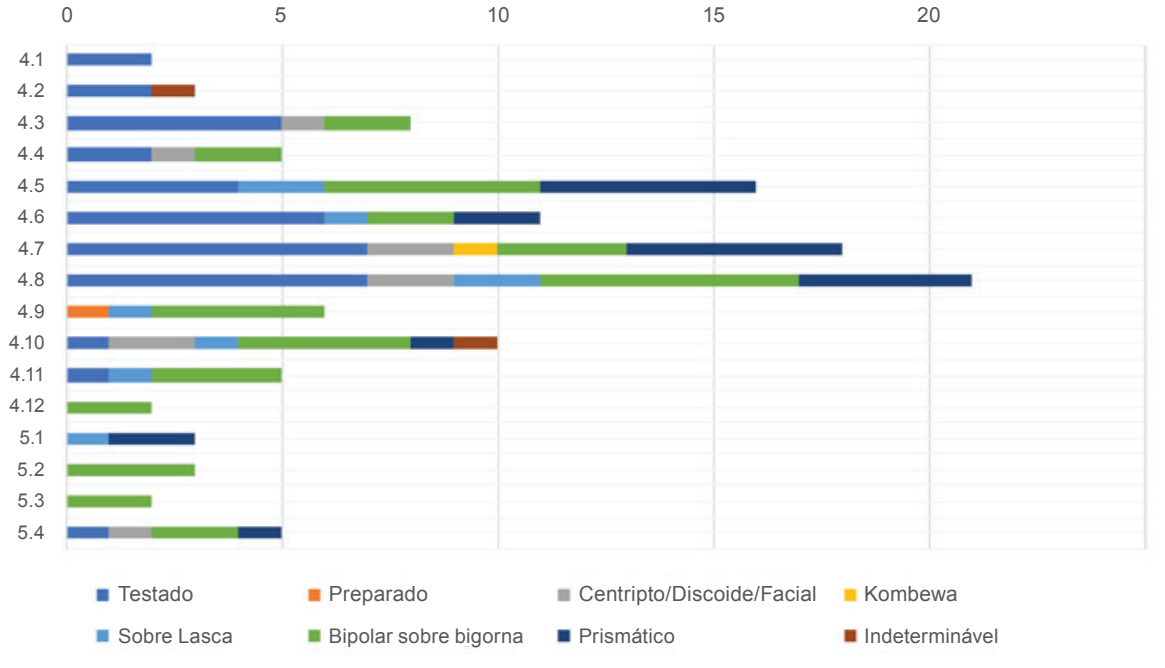

Tipo de núcleo Vs tipo de quartzo

60

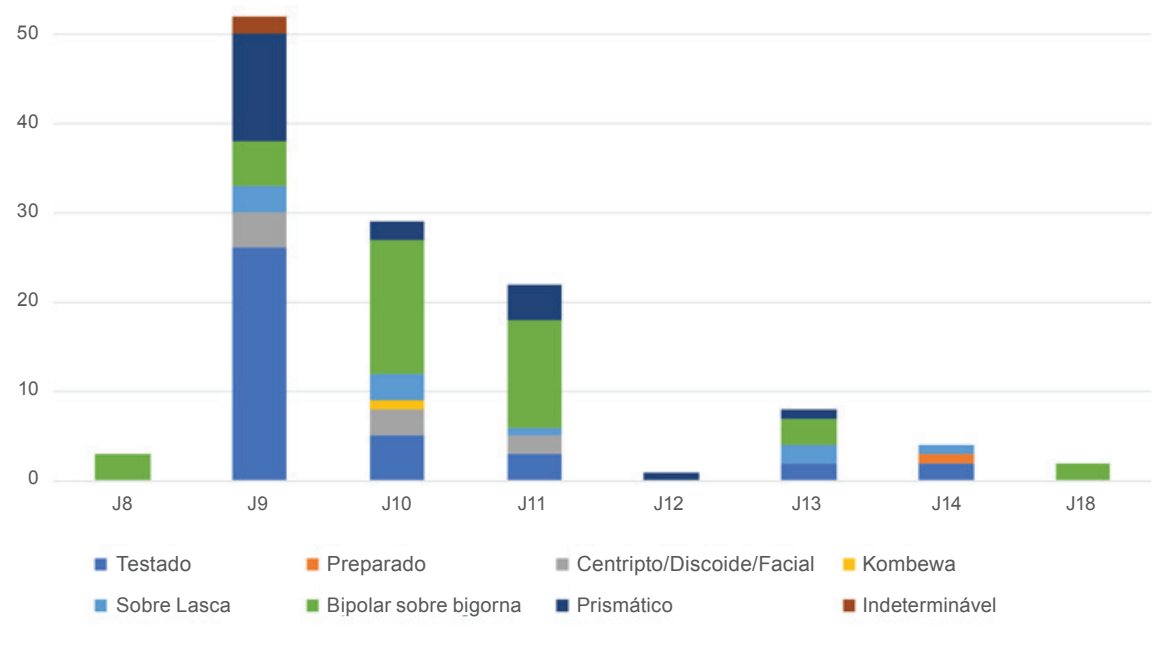

Figura 4 - Núcleos em quartzo da área Z/A'-6-8 da Cardina: estratégia de debitagem ao longo da sequência estratigráfica e relação entre estratégia de debitagem e tipo de quartzo.

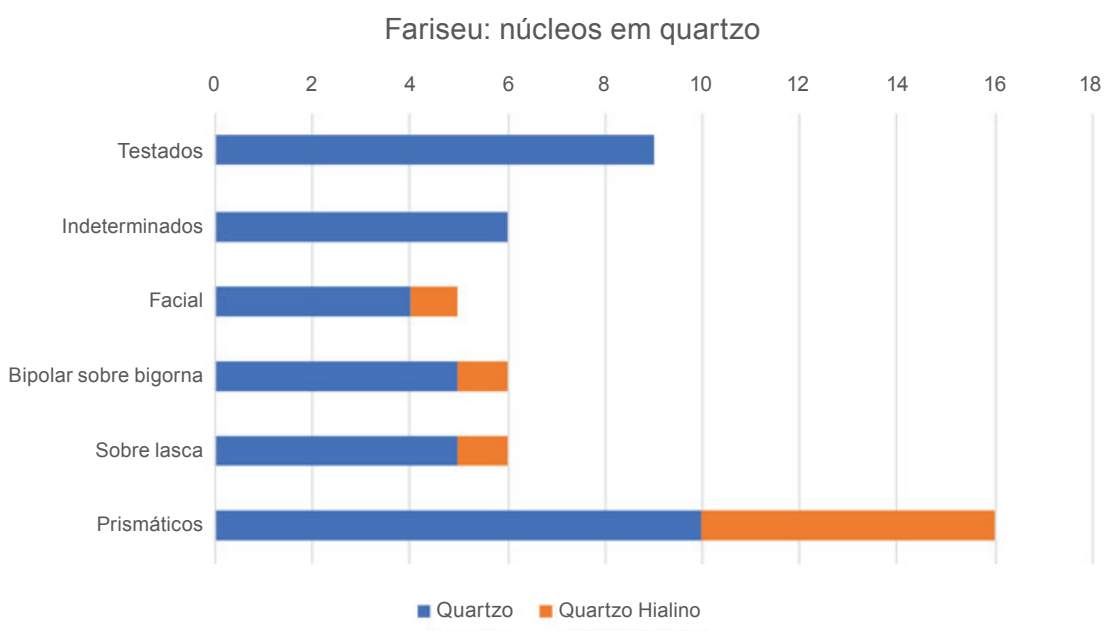

Figura 5 - Estratégia de debitagem utilizada nos núcleos em quartzo da UE4 do Fariseu. 


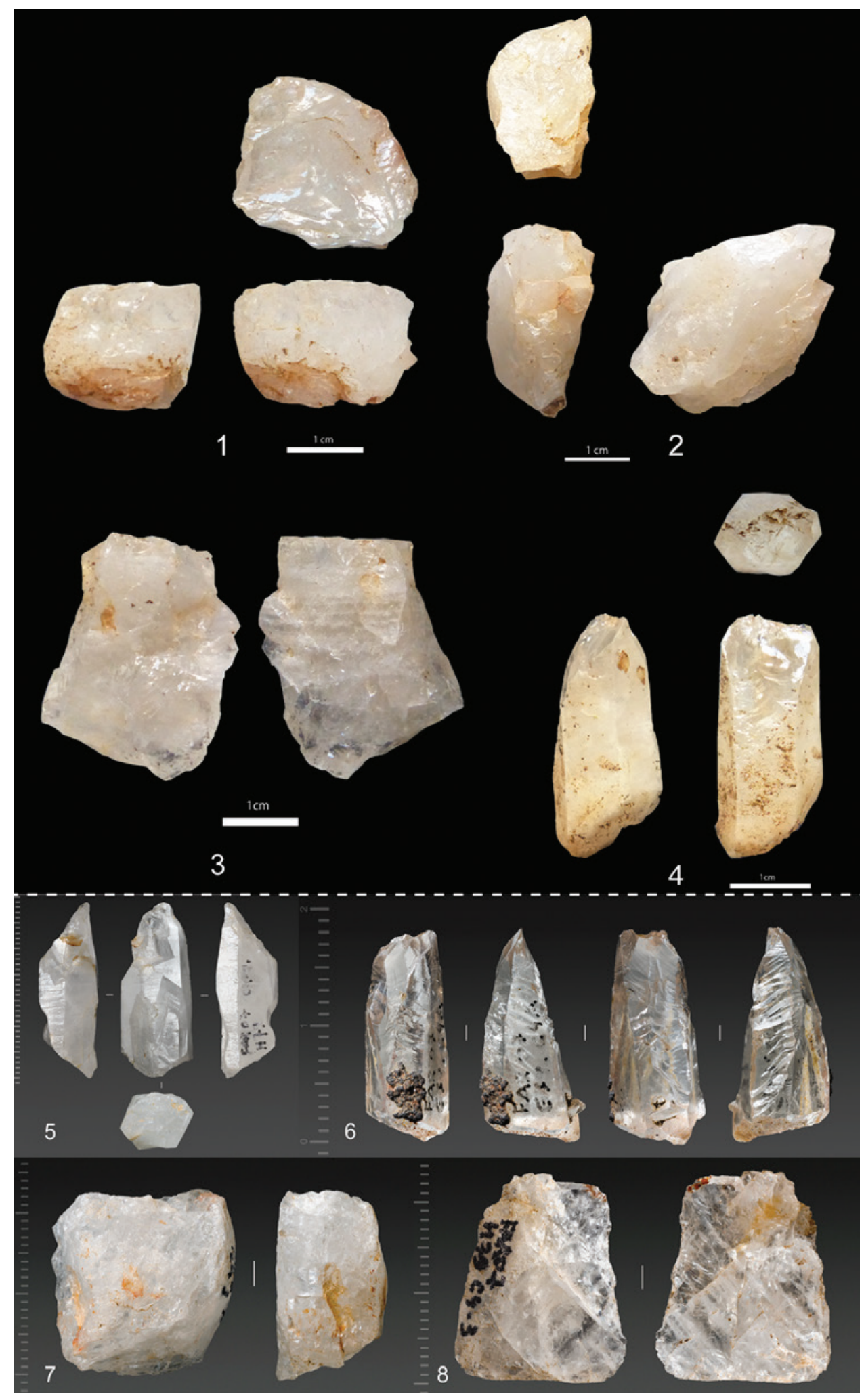

Figura 6- Núcleos em quartzo da Cardina: 1- núcleo para lamelas sobre seixo de quartzo (Ji1), com progressão da debitagem semi-giratória, UE4 NA6; 2- núcleo para lamelas sobre fragmento de quartzo (J10), exploração frontal, UE 5 NA4; 3 - núcleo bipolar sobre bigorna em quartzo (J14), UE4 NA5; 4 - cristal de rocha (J13) com preparação do plano de percussão a 45ㅜㅡㄴ UE4 NA3. Núcleos em quartzo da UE4 do Fariseu: 5 - cristal de rocha (J13) com preparação do plano de percussão a 45우 6 - núcleo para lamelas em cristal de rocha (J13) com progressão da debitagem giratória; 7 - Núcleo bipolar sobre bigorna em quartzo (J1o); 8 - Peça esquirolada em quartzo (J11). Fotografias Cristina Gameiro \& José Paulo Ruas (Fariseu). 
Vau: núcleos em quartzo

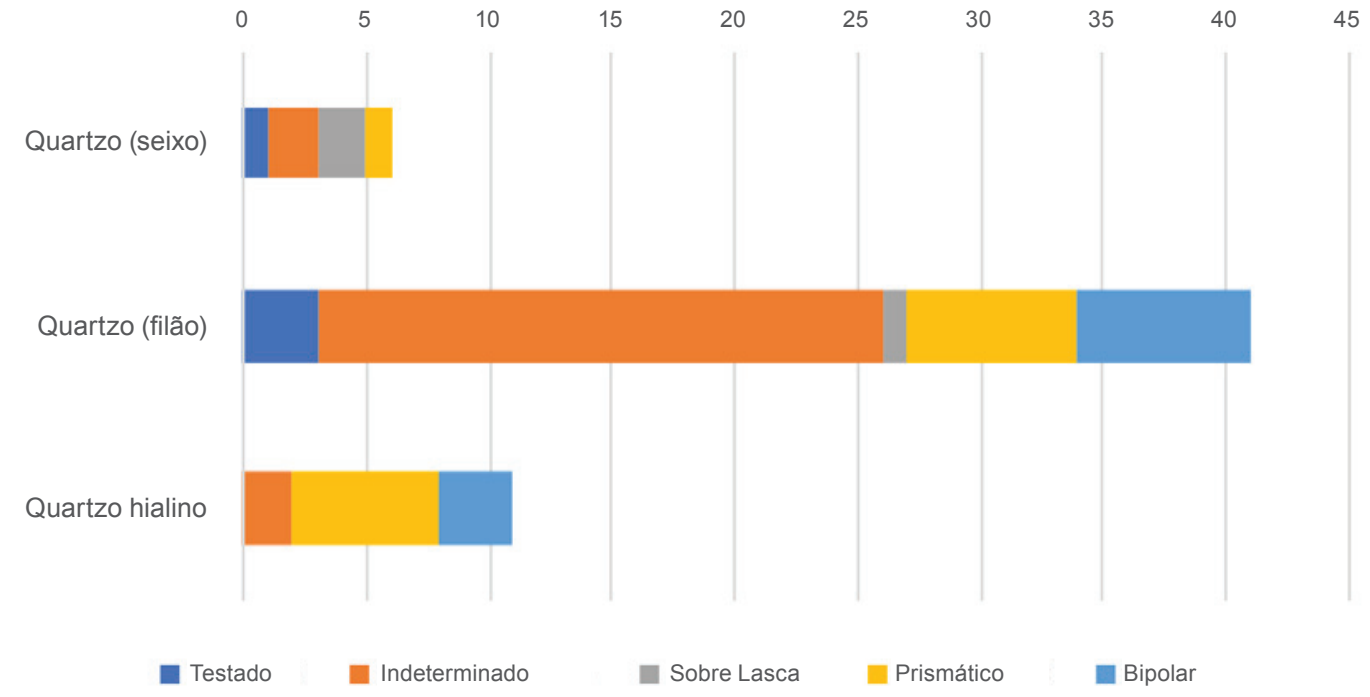

Rôdo: núcleos em quartzo

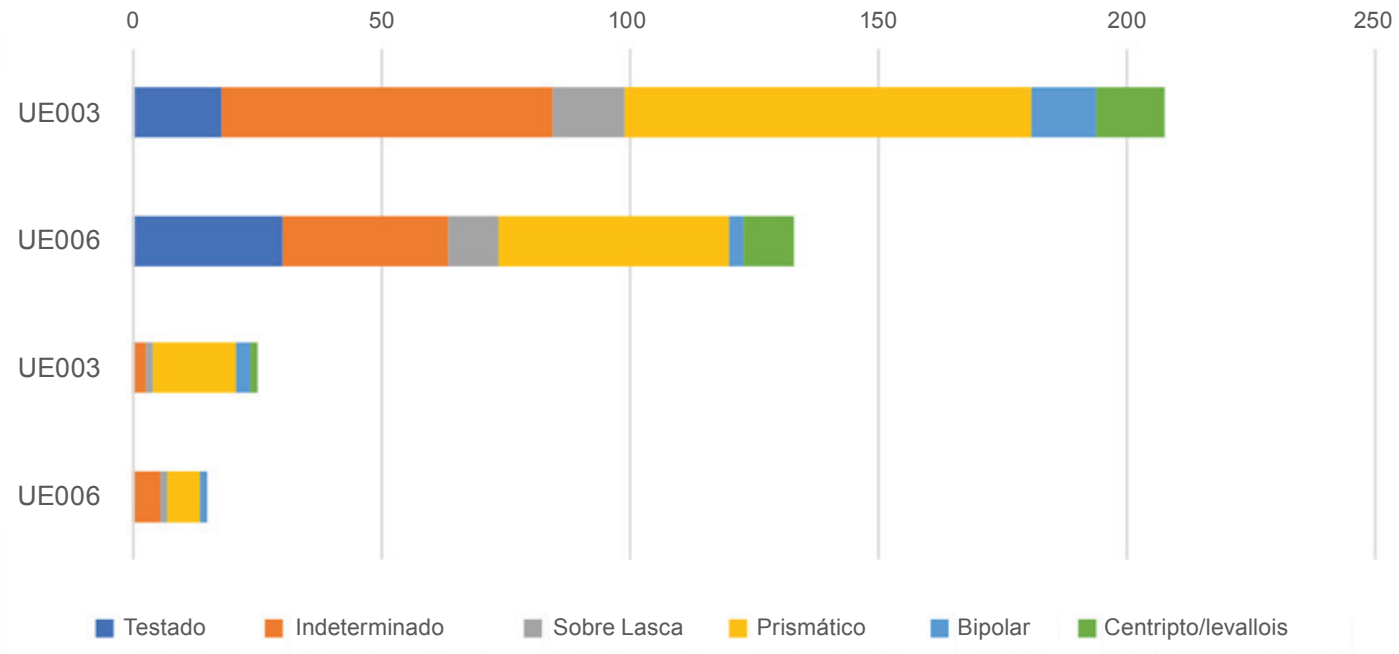

Figura 7 - Estratégia de debitagem utilizada nos núcleos em quartzo da UEoo5 do Vau (em cima) e das UEoo3 e UEoo5 do Rôdo (em baixo). De notar que no gráfico relativo ao Rôdo as duas primeiras barras concernem o quartzo e as duas últimas barras o quartzo hialino. 


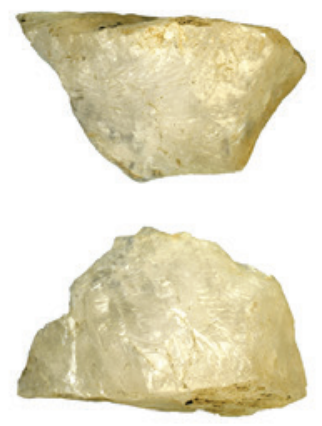

1

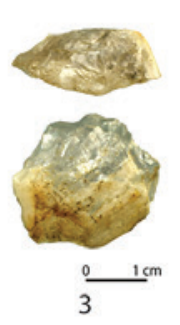

3

$1 \mathrm{~cm}$
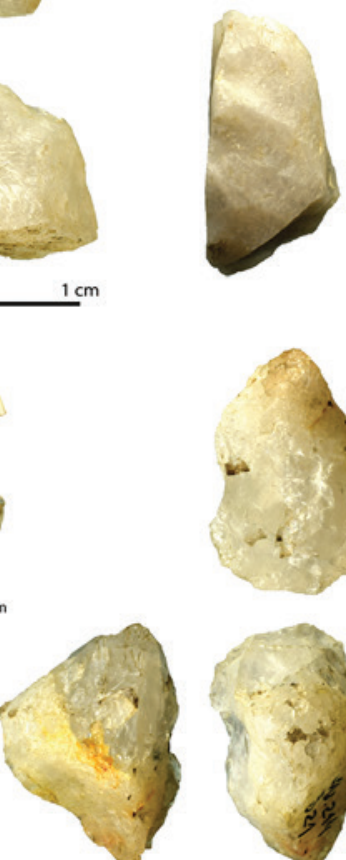

4

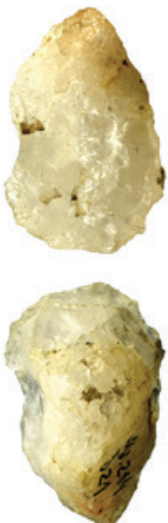

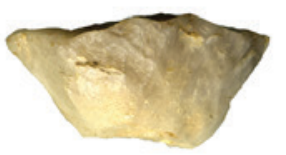
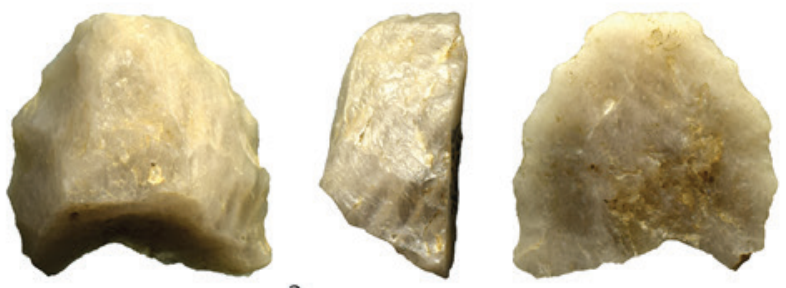

$0 \quad 1 \mathrm{~cm}$
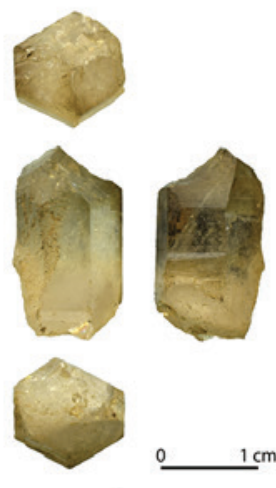

5
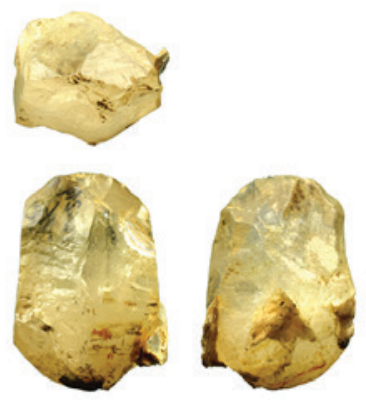

$0 \quad 1 \mathrm{~cm}$

6

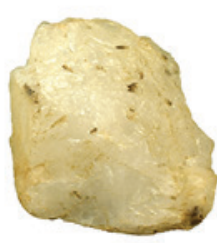

7

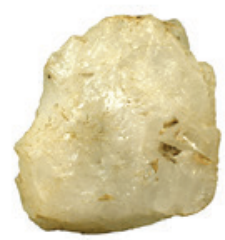

을 $1 \mathrm{~cm}$
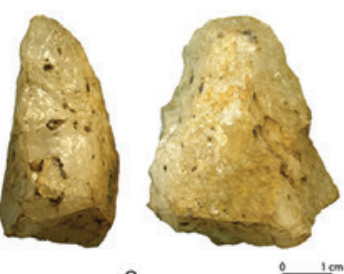

8
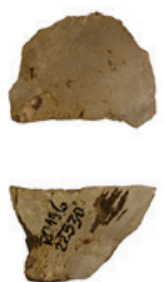

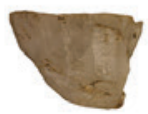

11
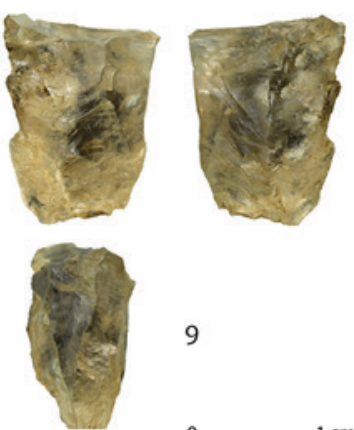

9

$1 \mathrm{~cm}$

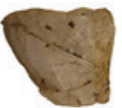

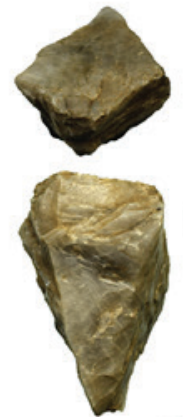

10
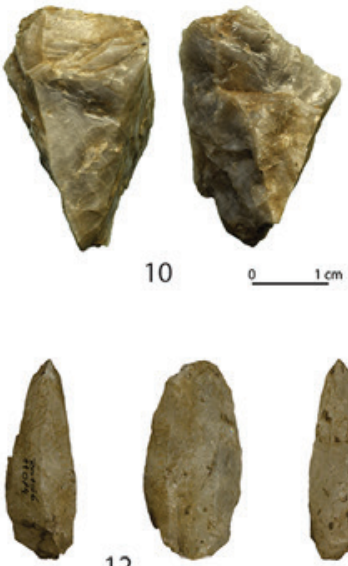

12
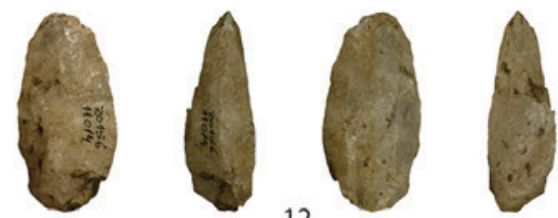

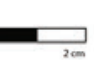

Figura 8 - Materiais em quartzo da UEoo5 do Vau: 1 - raspadeira sobre lasca; 2- raspadeira carenada atípica ou núcleo para pequenas lascas; 3- núcleo para pequenas lascas; 4-núcleo sobre lascas /raspadeira carenada para lamelas; Materiais em quartzo da UEoo3 do Vau: 5 - cristal com preparação do plano de percussão e sem debitagem; 6 - cristal testado e abandonado. Materiais em quartzo da UEoo6 do Rôdo: 7 - peça esquirolada; 8 - denticulado ou núcleo sobre lasca para produção de pequenas lascas; Materiais em quartzo da UEoo3 do Rôdo: 9 - núcleo bipolar sobre bigorna; 10 - núcleo sobre lasca para produção de lamelas, abandonado devido à existência de ressaltos; 11 - núcleo prismático para lamelas; 12 - núcleo prismático para a produção de lamelas. Fotografias Carmen Manzano \& Rui Oliveira / Arqueologia \& Património. 
Vale do Côa
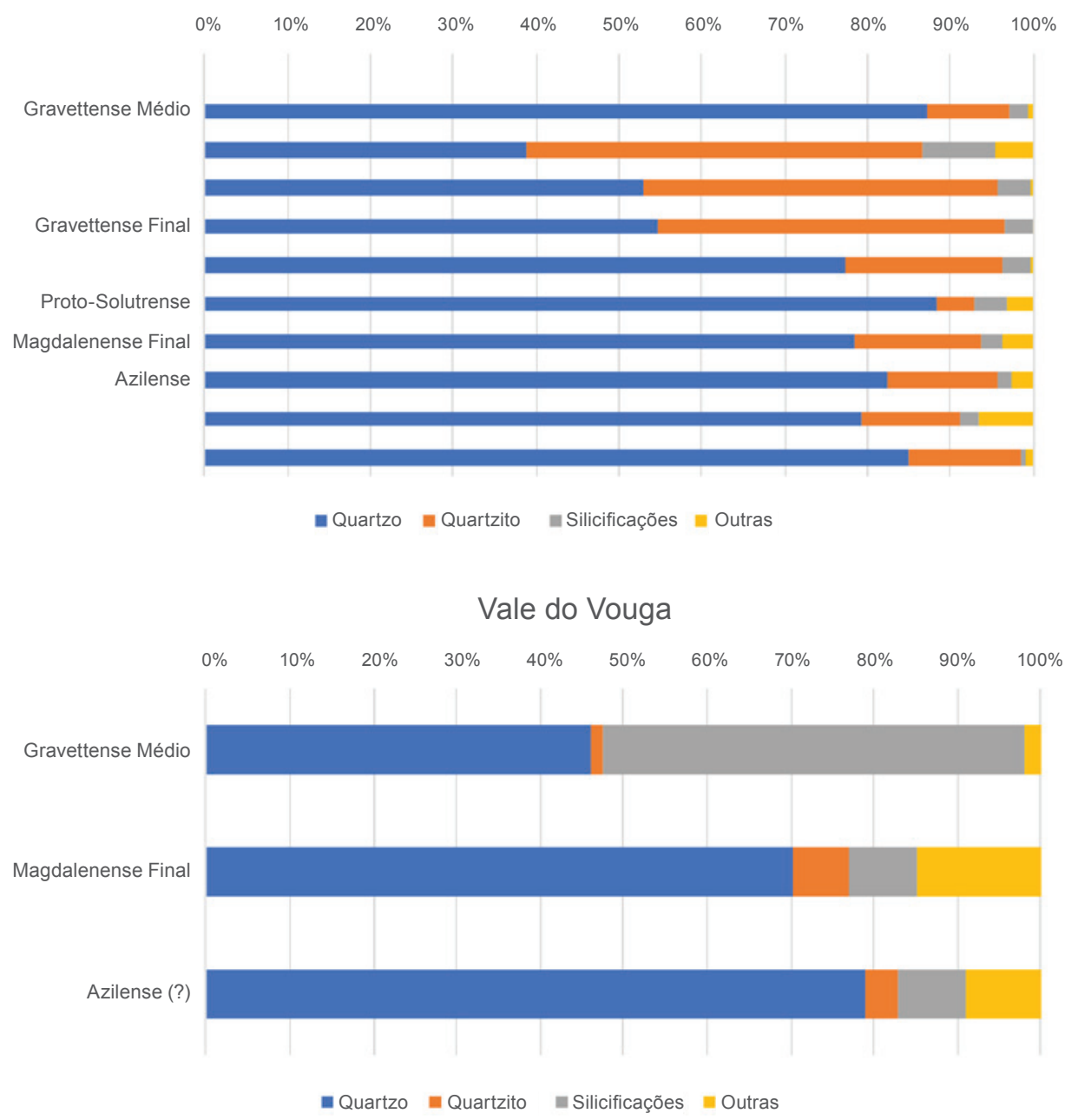

Figura 9-Comparação entre a percentagem de utilização das diferentes matérias-primas do Gravettense médio ao Azilense no Vale do Côa e no Vale do Vouga.

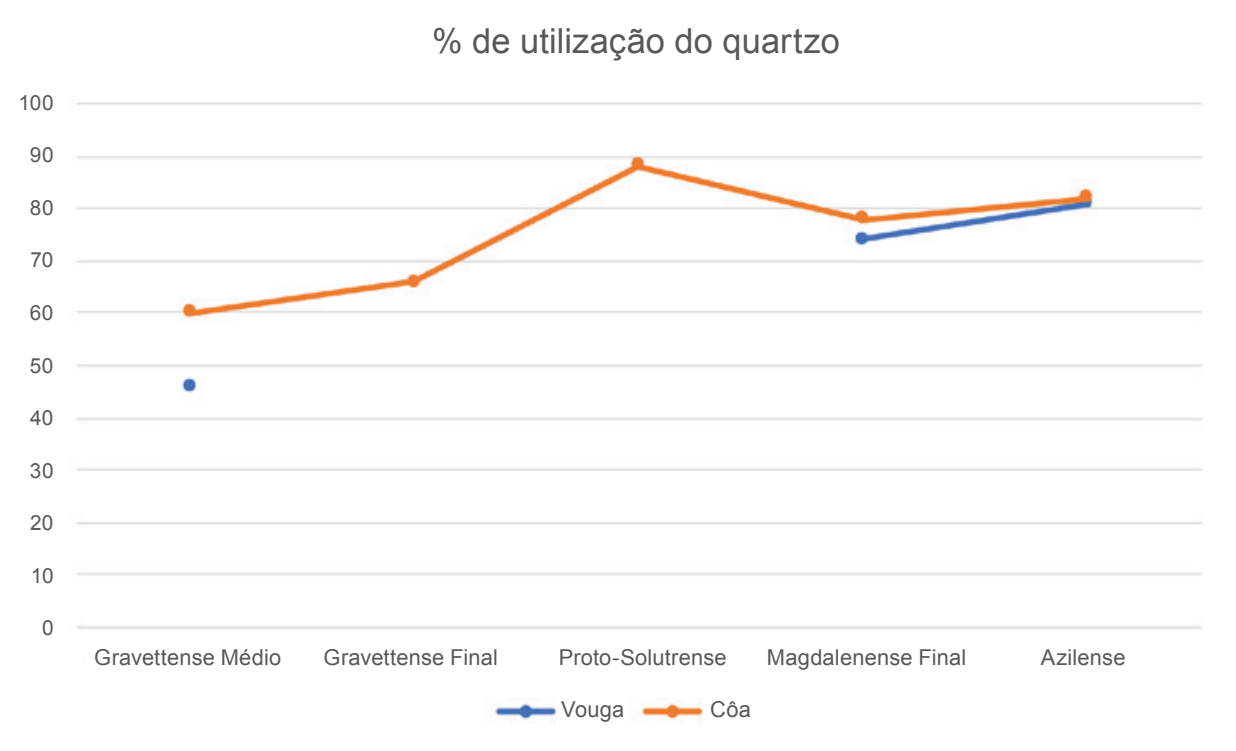

Figura 1o - Comparação da percentagem média de utilização do quartzo durante as diferentes fases do Paleolítico Superior. 


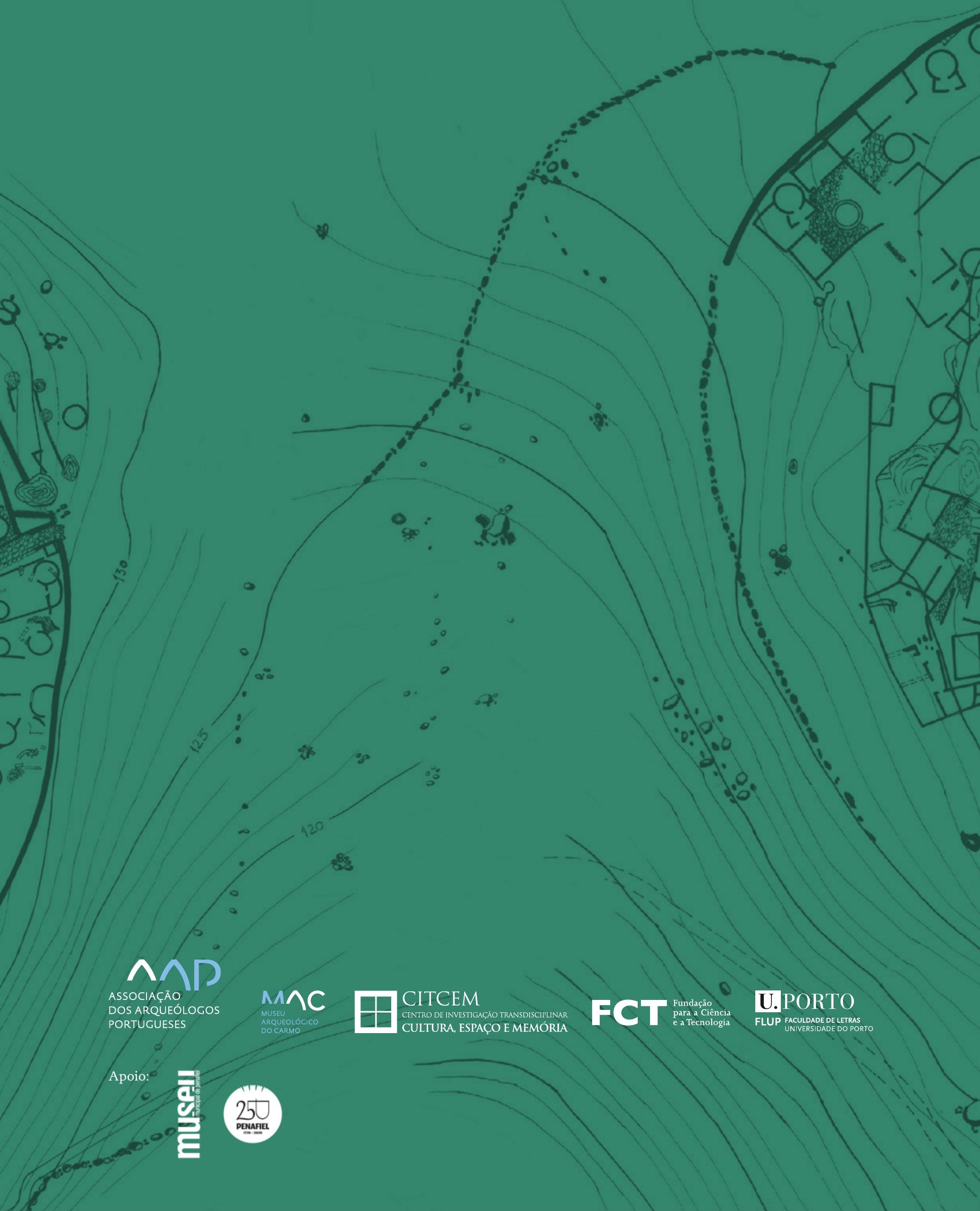

